Check for updates

Cite this: Chem. Sci., 2018, 9, 8291

๑ All publication charges for this article have been paid for by the Royal Society of Chemistry

Received 22nd May 2018

Accepted 28th August 2018

DOI: $10.1039 / c 8 s c 02256 a$

rsc.li/chemical-science

\section{Degradable polymer prodrugs with adjustable activity from drug-initiated radical ring-opening copolymerization $\uparrow$}

\author{
Elise Guégain, (D) Johanna Tran, (D) Quentin Deguettes and Julien Nicolas (D)*
}

Degradable polymer prodrugs based on gemcitabine (Gem) as an anticancer drug were synthesized by 'drug-initiated' nitroxide-mediated radical ring-opening copolymerization (NMrROP) of methacrylic esters and 2-methylene-4-phenyl-1,3-dioxolane (MPDL). Different structural parameters were varied to determine the best biological performances: the nature of the monomer [i.e., oligo(ethylene glycol) methacrylate (OEGMA) or methyl methacrylate (MMA)], the nature of the Gem-polymer linker (i.e., amide or amide and diglycolate) and the MPDL content in the copolymer. Depending on the nature of the methacrylate monomer, two small libraries of water-soluble copolymer prodrugs and nanoparticles were obtained $\left(M_{\mathrm{n}} \sim 10000 \mathrm{~g} \mathrm{~mol}^{-1}, \Xi=1.1-1.5\right)$, which exhibited tunable hydrolytic degradation under accelerated conditions governed by the MPDL content. Drug-release profiles in human serum and in vitro anticancer activity on different cell lines enabled preliminary structure-activity relationships to be established. The cytotoxicity was independently governed by: (i) the MPDL content - the lower the MPDL content, the greater the cytotoxicity; (ii) the nature of the linker - the presence of a labile diglycolate linker enabled a greater Gem release compared to a simple amide bond and (iii) the hydrophilicity of the methacrylate monomer-OEGMA enabled a greater anticancer activity to be obtained compared to MMA-based polymer prodrugs. Remarkably, the optimal structural parameters enabled reaching the cytotoxic activity of the parent (free) drug.

\section{Introduction}

In the field of nanomedicine, use of drug-loaded polymer nanocarriers is considered as a promising strategy to improve the efficacy of drugs such as chemotherapeutics. ${ }^{\mathbf{1 , 2}}$ Traditionally, drugs are physically encapsulated during the nanocarrier formulation and thus simply entrapped into the polymer matrix. These drug delivery systems lead to protection of the drug from rapid metabolization, to longer circulation time, to lower toxicity toward healthy cells/tissues and open the door to active targeting by their surface-functionalization using biologically active ligands. Despite major advances and encouraging results, important limitations remain that may explain the small number of marketed nanomedicines and recent clinical trial disappointments: (i) the "burst-release", that is, the quick and uncontrolled release of a significant fraction of the drug post-injection; (ii) the poor drug-loadings, usually only a few percent and (iii) the crystallization of some drugs into the polymer matrix. These three different events can lead

Institut Galien Paris-Sud, CNRS UMR 8612, Univ Paris-Sud, Faculté de Pharmacie, 5 rue Jean-Baptiste Clément, 92290 Châtenay-Malabry, France. E-mail:julien.nicolas@ u-psud.fr; Tel: +331468358 53; Web: www.twitter.com/julnicolas

$\dagger$ Electronic supplementary information (ESI) available. See DOI: $10.1039 / \mathrm{c} 8 \mathrm{sc} 02256 \mathrm{a}$ to prohibitive toxicity and/or colloidal instability of the nanocarriers.

The prodrug strategy, which consists in coupling the drug to the nanocarrier, can be used to circumvent, or at least alleviate, the above-mentioned issues. ${ }^{3}$ Among the different synthetic pathways to produce polymer prodrug nanocarriers, the most used are certainly the "grafting to" and "grafting from" approaches that consist in functionalization of the preformed polymer or monomer, respectively. The emerging "grafting from" strategy (also called "drug-initiated"), that relies on the controlled growth of a short polymer chain from a drug, used as an initiator, has appealing benefits: ${ }^{4}$ (i) the synthesis and purification are simple because only a few synthetic steps are necessary; (ii) the resulting materials have a simple, welldefined structure (one drug attached at the extremity of each polymer chain); (iii) high drug loadings can be easily reached by targeting short polymer chains; (iv) this approach can be applied to different pathologies simply by changing the nature of the drug and (v) the properties of the resulting polymer prodrug can be finely tuned by changing the nature of the growing polymer.

The robustness of the drug-initiated method has been illustrated by its application to the synthesis of a variety of different polymer prodrugs constructed by either ring-opening polymerization $(\mathrm{ROP})^{5-9}$ or reversible-deactivation radical 
polymerization (RDRP), ${ }^{\mathbf{1 0}-\mathbf{1 8}}$ including nitroxide-mediated radical polymerization $(\mathrm{NMP})^{\mathbf{1 9}}$ or reversible additionfragmentation chain transfer (RAFT) polymerization. ${ }^{20}$ Whereas ROP generated degradable polyester prodrug nanocarriers, they exhibited poor colloidal stability and required post-stabilization by means of macromolecular surfactants, which is a major drawback. Also, no in vivo anticancer activity has been reported from these systems. On the other hand, RDRP-constructed polymer prodrugs gave promising anticancer efficacy in vivo, relied on simpler polymerization methods (e.g., no stringent conditions, commercially available controlling agents) and offered much more versatility regarding the nature of the polymer used. However, they are not degradable because of the carbon-carbon backbone of the vinyl polymer chains. This represents an important drawback because nondegradable materials may accumulate in the body, leading to prohibitive toxicity in case chronic/repeated administration is envisioned. A global strategy combining both the advantages of ROP and RDRP for the design of efficient polymer prodrugs by the "drug-initiated" approach is thus highly desirable.

Conferring degradability to vinyl materials is currently the focus of intensive work. ${ }^{21}$ This research topic is crucial given the numerous systems based on vinyl polymers devoted to biomedical applications regularly being reported in the literature. Among the different synthetic strategies, radical ringopening polymerization (rROP) appears to be the method of choice for incorporating labile groups into the polymer backbone and enabling significant degradation. ${ }^{22,23}$ Thanks to its radical ring-opening mechanism, rROP possesses both the versatility and simplicity of radical polymerization, together with the ability to introduce functional groups into the polymer backbone. Among the different classes of monomers that have been polymerized by rROP, cyclic ketene acetals (CKAs) are the most-studied family. Although their homopolymerization has been extensively studied in the $80 \mathrm{~s},{ }^{\mathbf{2 4 - 2 7}}$ they aroused renewed interest over the past decade as comonomers to confer degradability to vinyl polymers via insertion of ester groups from either free-radical copolymerization ${ }^{28-34}$ or RDRP. ${ }^{32,35-45}$ Other cyclic monomers deriving from cyclic allylic sulfides ${ }^{46-48}$ have also been used to incorporate cleavable ester, thioester, and disulfide functionalities into the polymer backbone through RAFT copolymerization with traditional vinyl monomers. ${ }^{41}$ Despite several applications of rROP-designed materials for biomedical applications, ${ }^{31,49-51}$ their use in the field of prodrug nanocarriers has only been reported from preformed functional copolymers via the "grafting to" approach. ${ }^{52,53}$

Herein, we report for the first time on a general approach that combines the best of two worlds, that is, the drug-initiated synthesis of degradable polymer prodrugs by rROP. We demonstrated that well-defined, degradable vinyl copolymers can be synthesized from an anticancer drug-bearing RDRP initiator by rROP, leading to nanocarriers, either water-soluble conjugates or nanoparticles (Fig. 1), with adjustable anticancer activity depending on the nature of both the drugpolymer linkage and the copolymer. Not only this new class of polymer prodrugs overcame a significant obstacle in the field, but it also disclosed important insights into the relevant parameters that govern the drug release kinetics and eventually the anticancer activity.

\section{Experimental section}

\section{Materials}

Gemcitabine ( $>98 \%$ ) was purchased from Carbosynth Limited (UK). Oligo(ethylene glycol) methyl ether methacrylate (MeOEGMA, $M_{\mathrm{n}}=300 \mathrm{~g} \mathrm{~mol}^{-1}$ ), styrene (S, 99\%), methyl methacrylate (MMA, 99\%) and toluene (anhydrous, 99.8\%) were purchased from Sigma-Aldrich (France) and used as received (except for MMA which was distilled under reduced pressure). 2-Methylene-4-phenyl-1,3-dioxolane (MPDL), ${ }^{54}$ 4-amino-1-[4(tert-butyl-dimethylsilanyloxy)-5-(tert-butyl-dimethyl-silanyloxymethyl)-3,3-difluorotetrahydro-furan-2-yl]-1 $H$-pyrimidin-2-one (TBDMS-Gem), ${ }^{15}$ alkoxyamines Gem-AMA-SG1 (ref. 10) and AMAdigly ${ }^{11}$ were prepared as reported elsewhere. Tetrabutylammonium

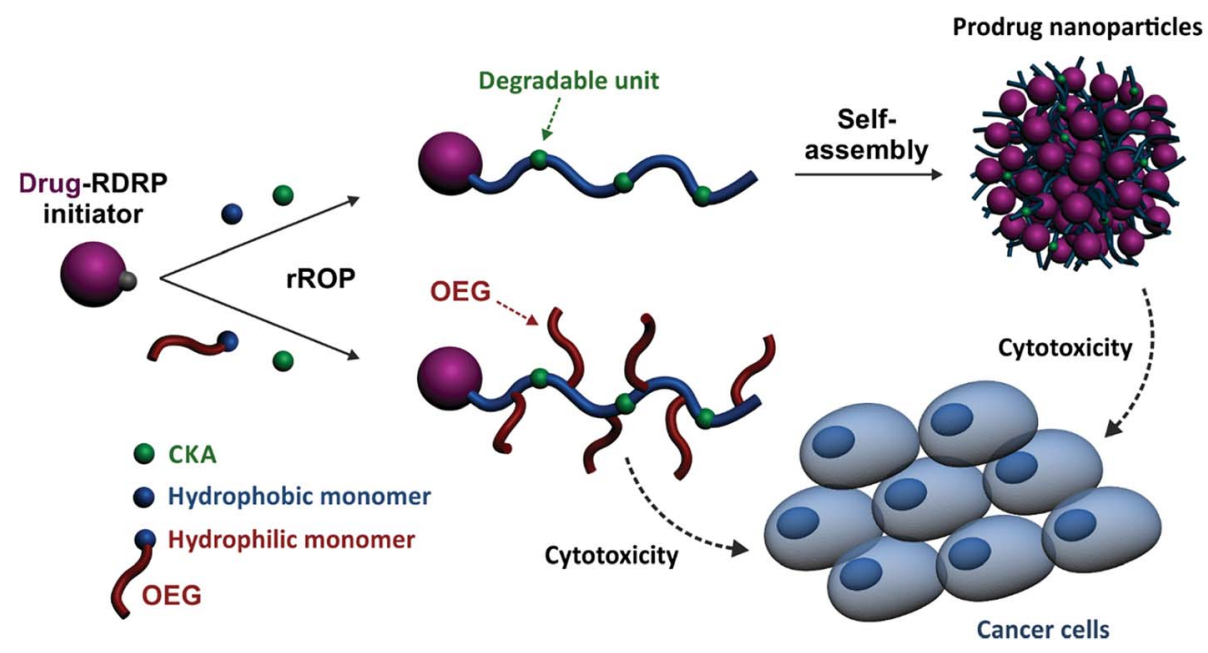

Fig. 1 Synthetic strategy for the design of degradable Gemcitabine-based polymer prodrugs by "drug-initiated" nitroxide-mediated radical ringopening copolymerization (NMrROP). 
fluoride (TBAF) was purchased from Alfa Aesar (a Johnson Matthey Co., France). Perfluoro-15-Crown-5-Ether (PFCE) was obtained from FluoroChem (UK). All other reactants were purchased from Sigma-Aldrich at the highest available purity and used as received. Deuterated chloroform $\left(\mathrm{CDCl}_{3}\right)$ and dimethyl sulfoxide (DMSO- $\left.\mathrm{d}_{6}\right)$ were obtained from Eurisotop. All other solvents were purchased from Carlo-Erba. Dulbecco's modified eagle's medium (DMEM) and fetal bovine serum (FBS) were purchased from Dulbecco (Invitrogen, France). Penicillin and streptomycin were obtained from Lonza (Verviers, Belgium). 2-Methyl-2-[N-tert-butyl- $N$-(1diethoxyphosphoryl-2,2-dimethylpropyl) aminoxy]propionic acid alkoxyamine (BlocBuilder MA, 99\%) and N-tert-butyl- $N$-(1diethylphosphono-2,2-dimethylpropyl) nitroxide (SG1, 85\%) were kindly supplied by Arkema.

\section{Analytical method}

Nuclear magnetic resonance (NMR) spectroscopy. NMR spectroscopy was performed in $5 \mathrm{~mm}$ diameter tubes in $\mathrm{CDCl}_{3}$ at $25{ }^{\circ} \mathrm{C}$. ${ }^{1} \mathrm{H}$ NMR or ${ }^{13} \mathrm{C}$ NMR spectroscopy was performed on a Bruker Avance 300 spectrometer at $300 \mathrm{MHz}\left({ }^{1} \mathrm{H}\right)$ or $75 \mathrm{MHz}$ $\left({ }^{13} \mathrm{C}\right)$. The chemical shift scale was calibrated based on the internal solvent signals. ${ }^{19} \mathrm{~F}$ NMR spectra were recorded on a Bruker Avance 400 at 376.5 MHz. The chemical shift scale was calibrated relative to an internal standard (PFCE, $\delta=-88 \mathrm{ppm}$ ).

Mass spectrometry (MS). Mass spectra were recorded with a Bruker Esquire-LC instrument. High-resolution (HR) mass spectra (electron spin ionization, ESI) were recorded on an ESI/TOF (LCT, Waters) LC-spectrometer. Elemental analyses were performed by the Service de microanalyse, Centre d'Etudes Pharmaceutiques, Châtenay-Malabry, France, with a PerkinElmer 2400 analyzer.

Size exclusion chromatography (SEC). SEC was performed at $30{ }^{\circ} \mathrm{C}$ with two columns from Polymer Laboratories (PL-gel MIXED-D; $300 \times 7.5 \mathrm{~mm}$; bead diameter, $5 \mu \mathrm{m}$; linear part, 400-400 $000 \mathrm{~g} \mathrm{~mol}^{-1}$ ) and a differential refractive index detector (Spectrasystem RI-150 from Thermo Electron Corp.), using chloroform $\left(\mathrm{CHCl}_{3}\right)$ as the eluent at a flow rate of $1 \mathrm{~mL} \mathrm{~min}{ }^{-1}$. Toluene was used as a flow-rate marker. The conventional calibration curve was based on poly(methyl methacrylate) (PMMA) standards (peak molar masses, $M_{\mathrm{p}}=625-625500 \mathrm{~g}$ $\mathrm{mol}^{-1}$ ) from Polymer Laboratories. This technique allowed $M_{\mathrm{n}}$ (number-average molar mass), $M_{\mathrm{w}}$ (weight-average molar mass), and $M_{\mathrm{w}} / M_{\mathrm{n}}$ (dispersity, $Ð$ ) to be determined.

Dynamic light scattering (DLS) and zeta potential. Nanoparticle diameters $\left(D_{\mathrm{z}}\right)$ and zeta potentials $(\zeta)$ were measured by dynamic light scattering (DLS) with a Nano ZS from Malvern $\left(173^{\circ}\right.$ scattering angle) at a temperature of $25{ }^{\circ} \mathrm{C}$. The surface charge of the nanoparticles was determined by $\zeta$-potential $(\mathrm{mV})$ measurement at $25{ }^{\circ} \mathrm{C}$ after dilution with $1 \mathrm{mM} \mathrm{NaCl}$, using the Smoluchowski equation.

Cryogenic transmission electron microscopy (cryo-TEM). The morphology of the nanoassemblies was observed by cryo-TEM. Briefly, $5 \mu \mathrm{L}$ of the nanoparticle suspension $\left(0.5 \mathrm{mg} \mathrm{mL} \mathrm{m}^{-1}\right)$ was deposited on a Lacey Formvar/carbon 300 mesh copper microscopy grid (Ted Pella). Most of the drop was removed with a blotting filter paper and the residual thin film remaining within the holes was vitrified by plunging into liquid ethane. Samples were then observed using a JEOL 2100HC microscope.

\section{Synthetic procedures}

Synthesis of Gem-digly-AMA-SG1. TBDMS-Gem $(3.0 \mathrm{~g}$, $6.1 \mathrm{mmol}$ ), AMA-digly (2.5 g, $4.7 \mathrm{mmol})$ and benzotriazol-1-yloxytripyrrolidinophosphonium hexafluorophosphate (РyBOP, $3.2 \mathrm{~g}, 6.1 \mathrm{mmol}$ ) were dissolved in $30 \mathrm{~mL}$ of dry DMF. $N, N$-Diisopropylethylamine (DIPEA, $2.2 \mathrm{~mL}, 12.4 \mathrm{mmol}$ ) was added dropwise. After stirring at $30{ }^{\circ} \mathrm{C}$ for $24 \mathrm{~h}$ in a nitrogen atmosphere, the mixture was poured into $200 \mathrm{~mL}$ of EtOAc. The organic phase was washed with $1 \mathrm{M} \mathrm{HCl}$, sat. $\mathrm{NaHCO}_{3}$ aqueous solution, and brine before being dried over $\mathrm{MgSO}_{4}$. The residue was concentrated under reduced pressure and purified by flash chromatography $\left(\mathrm{SiO}_{2}\right.$, gradient elution from EtOAc/petroleum ether $=1 / 1, \mathrm{v} / \mathrm{v}$ to EtOAc) to give $2.01 \mathrm{~g}$ of Gem-digly-AMA-SG1 as a white/slightly orange solid (Fig. S1†). Yield $=42 \% .{ }^{1} \mathrm{H}$ NMR $\left(\mathrm{CDCl}_{3}, 300 \mathrm{MHz}\right)$ : major diastereomer: $\delta=8.11\left(1 \mathrm{H}, \mathrm{s}, \mathrm{H}_{6}\right), 7.41$ $\left(1 \mathrm{H}, \mathrm{s}, \mathrm{H}_{5}\right), 6.36\left(1 \mathrm{H}, \mathrm{s}, \mathrm{H}_{1^{\prime}}\right), 4,60\left(1 \mathrm{H}, \mathrm{q}, \mathrm{H}_{\mathrm{b}}\right), 3.75-4.50(16 \mathrm{H}, \mathrm{m}$, $\left.\mathrm{H}_{\mathrm{a}}, \mathrm{H}_{\mathrm{g}}, \mathrm{H}_{3^{\prime}}, \mathrm{H}_{4^{\prime}}, \mathrm{H}_{5^{\prime}}\right), 3.26\left(1 \mathrm{H}, \mathrm{d}, \mathrm{H}_{\mathrm{f}}\right), 1.48\left(3 \mathrm{H}, \mathrm{d}, \mathrm{H}_{\mathrm{c}}\right), 1.29(6 \mathrm{H}$, t, $\left.\mathrm{H}_{\mathrm{h}}\right), 1.10\left(18 \mathrm{H}, \mathrm{s}, \mathrm{H}_{\mathrm{e}}\right), 0.90\left(18 \mathrm{H}, \mathrm{s}, \mathrm{H}_{\mathrm{i}}\right), 0.13\left(12 \mathrm{H}, \mathrm{s}, \mathrm{H}_{\mathrm{j}}\right) \mathrm{ppm}$. Minor diastereomer: $\delta=8.10\left(1 \mathrm{H}, \mathrm{s}, \mathrm{H}_{6}\right), 7.43\left(1 \mathrm{H}, \mathrm{s}, \mathrm{H}_{5}\right), 6.34$ $\left(1 \mathrm{H}, \mathrm{s}, \mathrm{H}_{1^{\prime}}\right), 4.60\left(1 \mathrm{H}, \mathrm{q}, \mathrm{H}_{\mathrm{b}}\right), 3.75-4.50\left(16 \mathrm{H}, \mathrm{m}, \mathrm{H}_{\mathrm{a}}, \mathrm{H}_{\mathrm{g}}, \mathrm{H}_{3^{\prime}}, \mathrm{H}_{4^{\prime}}\right.$, $\left.\mathrm{H}_{5^{\prime}}\right), 3.35\left(1 \mathrm{H}, \mathrm{d}, \mathrm{H}_{\mathrm{f}}\right), 1.50\left(3 \mathrm{H}, \mathrm{d}, \mathrm{H}_{\mathrm{c}}\right), 1.29\left(6 \mathrm{H}, \mathrm{t}, \mathrm{H}_{\mathrm{h}}\right), 1.15$ $\left(18 \mathrm{H}, \mathrm{s}, \mathrm{H}_{\mathrm{e}}\right), 0.95\left(18 \mathrm{H}, \mathrm{s}, \mathrm{H}_{\mathrm{i}}\right), 0.10\left(12 \mathrm{H}, \mathrm{s}, \mathrm{H}_{\mathrm{j}}\right) \mathrm{ppm} .{ }^{13} \mathrm{C} \mathrm{NMR}$ $\left(\mathrm{CDCl}_{3}, 75 \mathrm{MHz}\right)$ : major diastereomer: $\delta=173.6\left(\mathrm{~s}, \mathrm{C}_{\mathrm{d}}\right), 169.4(\mathrm{~s}$, $\left.\mathrm{C}_{\mathrm{k}}\right), 169.2\left(\mathrm{~s}, \mathrm{C}_{\mathrm{j}}\right), 161.8\left(\mathrm{~s}, \mathrm{C}_{4}\right), 154.9\left(\mathrm{~s}, \mathrm{C}_{2}\right), 144.3\left(\mathrm{~s}, \mathrm{C}_{6}\right), 121.9(\mathrm{~s}$, $\left.\mathrm{C}_{2^{\prime}}\right), 96.5\left(\mathrm{~s}, \mathrm{C}_{5}\right), 84.9\left(\mathrm{~d}, \mathrm{C}_{1^{\prime}}\right), 82.3\left(\mathrm{~s}, \mathrm{C}_{\mathrm{b}}\right), 81.4\left(\mathrm{~s}, \mathrm{C}_{4^{\prime}}\right), 70.9\left(\mathrm{~s}, \mathrm{C}_{\mathrm{a}}\right)$, $70.2\left(\mathrm{t}, \mathrm{C}_{3^{\prime}}\right), 68.0\left(\mathrm{~s}, \mathrm{C}_{\mathrm{a}}\right), 63.0\left(\mathrm{~s}, \mathrm{C}_{5^{\prime}}\right), 61.7\left(\mathrm{t}, \mathrm{C}_{\mathrm{g}}\right), 60.0\left(\mathrm{~s}, \mathrm{C}_{\mathrm{a}}\right), 58.9$ $\left(\mathrm{d}, \mathrm{C}_{\mathrm{g}}\right), 35.5\left(\mathrm{~d}, \mathrm{C}_{\mathrm{l}}\right), 29.6\left(\mathrm{~d}, \mathrm{C}_{\mathrm{g}}\right), 27.9\left(\mathrm{~s}, \mathrm{C}_{\mathrm{e}}\right), 25.7\left(\mathrm{~d}, \mathrm{C}_{\mathrm{e}}\right), 19.3$ (s, $\left.\mathrm{C}_{\mathrm{c}}\right), 18.3\left(\mathrm{~s}, \mathrm{C}_{\mathrm{i}}\right), 17.9\left(\mathrm{~s}, \mathrm{C}_{\mathrm{m}}\right), 16.5\left(\mathrm{~d}, \mathrm{C}_{\mathrm{h}}\right)$ ppm. Minor diastereomer: $\delta=172.6\left(\mathrm{~s}, \mathrm{C}_{\mathrm{d}}\right), 169.3\left(\mathrm{~s}, \mathrm{C}_{\mathrm{k}}\right), 169.1\left(\mathrm{~s}, \mathrm{C}_{\mathrm{j}}\right), 161.9\left(\mathrm{~s}, \mathrm{C}_{4}\right)$, $154.9\left(\mathrm{~s}, \mathrm{C}_{2}\right), 144.2\left(\mathrm{~s}, \mathrm{C}_{6}\right), 121.9\left(\mathrm{~s}, \mathrm{C}_{2^{\prime}}\right), 96.6\left(\mathrm{~s}, \mathrm{C}_{5}\right), 84.4\left(\mathrm{~d}, \mathrm{C}_{1^{\prime}}\right)$, $82.3\left(\mathrm{~s}, \mathrm{C}_{\mathrm{b}}\right), 81.5\left(\mathrm{~s}, \mathrm{C}_{4^{\prime}}\right), 70.9\left(\mathrm{~s}, \mathrm{C}_{\mathrm{a}}\right), 69.5\left(\mathrm{t}, \mathrm{C}_{3^{\prime}}\right), 68.3\left(\mathrm{~s}, \mathrm{C}_{\mathrm{a}}\right), 63.0$ $\left(\mathrm{s}, \mathrm{C}_{5^{\prime}}\right), 62.0\left(\mathrm{t}, \mathrm{C}_{\mathrm{g}}\right), 60.0\left(\mathrm{~s}, \mathrm{C}_{\mathrm{a}}\right), 59.1\left(\mathrm{~d}, \mathrm{C}_{\mathrm{g}}\right), 35.2\left(\mathrm{~d}, \mathrm{C}_{\mathrm{l}}\right), 30.1(\mathrm{~d}$, $\left.\mathrm{C}_{\mathrm{g}}\right), 28.0\left(\mathrm{~s}, \mathrm{C}_{\mathrm{e}}\right), 25.7\left(\mathrm{~d}, \mathrm{C}_{\mathrm{e}}\right), 19.3\left(\mathrm{~s}, \mathrm{C}_{\mathrm{c}}\right), 18.3\left(\mathrm{~s}, \mathrm{C}_{\mathrm{i}}\right), 18.0\left(\mathrm{~s}, \mathrm{C}_{\mathrm{m}}\right)$, $16.2\left(\mathrm{~d}, \mathrm{C}_{\mathrm{h}}\right)$ ppm. ${ }^{19} \mathrm{~F} \mathrm{NMR}\left(\mathrm{CDCl}_{3}, 376.5 \mathrm{MHz}\right): \delta=-117 \mathrm{ppm}$. MS (ESI): $m / z=999.5(\mathrm{M}-\mathrm{H})^{-}$. Calc. for $\mathrm{C}_{43} \mathrm{H}_{79} \mathrm{~F}_{2} \mathrm{~N}_{4} \mathrm{O}_{14} \mathrm{PSi}_{2}$ : 1001.

Synthesis of Gem-poly[(oligo(ethylene glycol) methyl ether methacrylate)-co-(2-methylene-4-phenyl-1,3-dioxolane)] (GemP(OEGMA-co-MPDL)). A typical solution copolymerization procedure $\left(f_{\text {MPDL }, 0}=0.2\right.$, expt 1$)$ is described as follows. In a $7 \mathrm{~mL}$ vial fitted with a rubber septum and a magnetic stirring bar, a mixture of OEGMA $\left(1.3214 \mathrm{~g}, 4.40 \mathrm{mmol}, M_{\mathrm{n}}=300 \mathrm{~g}\right.$ $\mathrm{mol}^{-1}$ ), MPDL (0.1786 g, $1.10 \mathrm{mmol}$ ), Gem-AMA-SG1 (28.0 mg, $\left.4.58 \times 10^{-2} \mathrm{mmol}\right)$, SG1 $\left(1.5 \mathrm{mg}, 4.39 \times 10^{-3} \mathrm{mmol}\right)$ and anhydrous toluene $(1.5 \mathrm{~g}, 1.73 \mathrm{~mL})$ was degassed under stirring by argon bubbling for $15 \mathrm{~min}$ at room temperature. The mixture was then immersed in a preheated oil bath at $90{ }^{\circ} \mathrm{C}$, corresponding to the time zero of the reaction (according to the small volume of solution and its quasi-instantaneous heating). Samples were periodically taken to monitor the OEGMA conversion by ${ }^{1} \mathrm{H}$ NMR spectroscopy and the macromolecular characteristics $\left(M_{\mathrm{n}}\right.$ and $\left.Ð\right)$ by SEC. The copolymer was then 
precipitated twice in a mixture of cold cyclohexane/petroleum ether $(1 / 1, v / v)$ and dried under high vacuum until constant weight. The same procedure was followed by adapting the amount of the reactants for $f_{\mathrm{MPDL}, 0}=0.4$ (expt 2) [OEGMA (1.1028 g, $3.68 \mathrm{mmol})$, MPDL (0.3972 g, $2.45 \mathrm{mmol})$, Gem-AMASG1 $\left(23.0 \mathrm{mg}, 3.76 \times 10^{-2} \mathrm{mmol}\right)$ and SG1 $\left(1.3 \mathrm{mg}, 3.80 \times 10^{-3}\right.$ $\mathrm{mmol})$ ] and $f_{\mathrm{MPDL}, 0}=0.7$ (expt 3) [OEGMA $(0.6633 \mathrm{~g}$, $2.21 \mathrm{mmol})$, MPDL (0.8367 g, $5.17 \mathrm{mmol})$, Gem-AMA-SG1 (13.8 mg, $\left.2.31 \times 10^{-2} \mathrm{mmol}\right)$ and SG1 (0.8 mg, $\left.\left.2.34 \times 10^{-3} \mathrm{mmol}\right)\right]$.

Synthesis of Gem-digly-poly[(oligo(ethylene glycol) methyl ether methacrylate)-co-(2-methylene-4-phenyl-1,3-dioxolane)] (Gem-digly-P(OEGMA-co-MPDL)). A typical solution copolymerization procedure $\left(f_{\text {MPDL }, 0}=0.2\right.$, expt $\left.1 \mathrm{~d}\right)$ is as follows. In a $7 \mathrm{~mL}$ vial, fitted with a rubber septum and a magnetic stirring bar, a mixture of OEGMA (1.3214 g, $4.40 \mathrm{mmol})$, MPDL (0.1786 g, $1.10 \mathrm{mmol})$, Gem-digly-AMA-SG1 (45.0 mg, $4.50 \times$ $\left.10^{-2} \mathrm{mmol}\right)$, SG1 $\left(1.5 \mathrm{mg}, 4.39 \times 10^{-3} \mathrm{mmol}\right)$ and anhydrous toluene $(1.5 \mathrm{~g}, 1.73 \mathrm{~mL}$ ) was degassed under stirring by argon bubbling for $15 \mathrm{~min}$ at room temperature. The mixture was then immersed in a preheated oil bath at $90{ }^{\circ} \mathrm{C}$. Samples were periodically taken to monitor the OEGMA conversion by ${ }^{1} \mathrm{H}$ NMR spectroscopy and the macromolecular characteristics $\left(M_{\mathrm{n}}\right.$ and $Ð)$ by SEC. The copolymer was then precipitated twice in a mixture of cold cyclohexane/petroleum ether $(1 / 1, v / v)$ and dried under high vacuum until constant weight. The same procedure was followed by adapting the amount of the reactants for $f_{\text {MPDL }, 0}=0.4$ (expt 2d) [OEGMA (1.1028 g, $\left.3.68 \mathrm{mmol}\right)$, MPDL (0.3972 g, $2.45 \mathrm{mmol})$, Gem-digly-AMA-SG1 $(38.0 \mathrm{mg}, 3.80 \times$ $\left.10^{-2} \mathrm{mmol}\right)$ and SG1 $\left.\left(1.3 \mathrm{mg}, 3.80 \times 10^{-3} \mathrm{mmol}\right)\right]$ and $f_{\text {MPDL }, 0}=$ 0.7 (expt 3d) [OEGMA (0.6633 g, $2.21 \mathrm{mmol})$, MPDL (0.8367 g, $5.17 \mathrm{mmol})$, Gem-digly-AMA-SG1 $\left(23.0 \mathrm{mg}, 2.30 \times 10^{-2} \mathrm{mmol}\right)$ and SG1 (0.8 mg, $\left.\left.2.34 \times 10^{-3} \mathrm{mmol}\right)\right]$.

Synthesis of Gem-poly[(methyl methacrylate)-co-(2-methylene4-phenyl-1,3-dioxolane)] (Gem-P(MMA-co-MPDL)). A typical solution copolymerization procedure $\left(f_{\mathrm{MPDL}, 0}=0.2\right.$, expt 4$)$ is as follows. In a $7 \mathrm{~mL}$ vial, fitted with a rubber septum and a magnetic stirring bar, a mixture of MMA (1.0673 g, $10.67 \mathrm{mmol})$, MPDL (0.4327 g, $2.67 \mathrm{mmol}$ ), Gem-AMA-SG1 (22.0 mg, $3.59 \times$ $\left.10^{-2} \mathrm{mmol}\right)$, SG1 $\left(1.3 \mathrm{mg}, 3.80 \times 10^{-3} \mathrm{mmol}\right)$ and anhydrous toluene $(1.5 \mathrm{~g}, 1.73 \mathrm{~mL})$ was degassed under stirring by argon bubbling for $15 \mathrm{~min}$ at room temperature. The mixture was then immersed in a preheated oil bath at $90{ }^{\circ} \mathrm{C}$. Samples were periodically taken to monitor the MMA conversion by ${ }^{1} \mathrm{H}$ NMR spectroscopy and the macromolecular characteristics $\left(M_{\mathrm{n}}\right.$ and $\left.\boxplus\right)$ by SEC. The copolymer was then precipitated twice in cold $\mathrm{MeOH}$ and dried under high vacuum until constant weight. The same procedure was followed by adapting the amount of the reactants for $f_{\mathrm{MPDL}, 0}=0.4$ (expt 5) [MMA (0.7215 g, $\left.7.22 \mathrm{mmol}\right)$, MPDL (0.7785 g, $4.81 \mathrm{mmol})$, Gem-AMA-SG1 (15.0 mg, $2.45 \times 10^{-2}$ $\mathrm{mmol})$ and SG1 $\left.\left(0.9 \mathrm{mg}, 2.49 \times 10^{-3} \mathrm{mmol}\right)\right]$ and $f_{\text {MPDL }, 0}=0.7$ (expt 6) [MMA (0.3135 g, $3.14 \mathrm{mmol}$ ), MPDL (1.1865 g, 7.32 mmol), Gem-AMA-SG1 $\left(6.5 \mathrm{mg}, 1.06 \times 10^{-2} \mathrm{mmol}\right)$ and SG1 $\left.\left(0.4 \mathrm{mg}, 1.02 \times 10^{-3} \mathrm{mmol}\right)\right]$.

Synthesis of Gem-digly-poly[(methyl methacrylate)-co-(2methylene-4-phenyl-1,3-dioxolane)] (Gem-digly-P(MMA-co-MPDL)). A typical solution copolymerization procedure $\left(f_{\text {MPDL }, 0}=0.2\right.$, expt $4 \mathrm{~d}$ ) is as follows. In a $7 \mathrm{~mL}$ vial, fitted with a rubber septum and a magnetic stirring bar, a mixture of MMA $(1.0673 \mathrm{~g}, 10.67 \mathrm{mmol})$, MPDL (0.4327 g, $2.67 \mathrm{mmol}$ ), Gem-digly-AMA-SG1 (36.0 mg, $3.60 \times$ $\left.10^{-2} \mathrm{mmol}\right)$, SG1 $\left(1.3 \mathrm{mg}, 3.80 \times 10^{-3} \mathrm{mmol}\right)$ and anhydrous toluene $(1.5 \mathrm{~g}, 1.73 \mathrm{~mL})$ was degassed under stirring by argon bubbling for $15 \mathrm{~min}$ at room temperature. The mixture was then immersed in a preheated oil bath at $90{ }^{\circ} \mathrm{C}$. Samples were periodically taken to monitor the MMA conversion by ${ }^{1} \mathrm{H}$ NMR spectroscopy and the macromolecular characteristics $\left(M_{\mathrm{n}}\right.$ and $\left.Ð\right)$ by SEC. The copolymer was then precipitated twice in cold $\mathrm{MeOH}$ and dried under high vacuum until constant weight. The same procedure was followed by adapting the amount of the reactants for $f_{\text {MPDL }, 0}=0.4$ (expt 5d) [MMA (0.7215 g, $7.22 \mathrm{mmol}$ ), MPDL (0.7785 g, $4.81 \mathrm{mmol})$, Gem-digly-AMA-SG1 $\left(25.0 \mathrm{mg}, 2.5 \times 10^{-2}\right.$ $\mathrm{mmol})$ and SG1 $\left.\left(0.9 \mathrm{mg}, 2.49 \times 10^{-3} \mathrm{mmol}\right)\right]$ and $f_{\mathrm{MPDL}, 0}=$ 0.7 (expt 6d) [MMA (0.3135 g, $3.14 \mathrm{mmol}$ ), MPDL (1.1865 g, $7.32 \mathrm{mmol})$, Gem-digly-AMA-SG1 (10.5 mg, $\left.1.05 \times 10^{-2} \mathrm{mmol}\right)$ and SG1 (0.4 mg, $\left.\left.1.02 \times 10^{-3} \mathrm{mmol}\right)\right]$.

Synthesis of low molar mass Gem-poly[(oligo(ethylene glycol) methyl ether methacrylate)-co-(2-methylene-4-phenyl1,3-dioxolane)] (Gem-P(OEGMA-co-MPDL)). Copolymers with a targeted $M_{\mathrm{n}}$ of $\sim 10000 \mathrm{~g} \mathrm{~mol}^{-1}$ were prepared by following a similar procedure to that of expt 1 but with a polymerization time of $8 \mathrm{~h}$. Experimental conditions were as follows: P1 $\left(f_{\text {MPDL }, 0}=0.2\right)$ [OEGMA (1.7618 g, $\left.5.87 \mathrm{mmol}\right)$, MPDL (0.2382 g, $1.47 \mathrm{mmol})$, Gem-AMA-SG1 (200.0 mg, $\left.3.27 \times 10^{-1} \mathrm{mmol}\right)$, SG1 $\left(12 \mathrm{mg}, 3.51 \times 10^{-2} \mathrm{mmol}\right)$ and anhydrous toluene $(2.0 \mathrm{~g}$, $2.31 \mathrm{~mL})$ ], P2 $\left(f_{\text {MPDL }, 0}=0.4\right)$ [OEGMA (1.4704 g, $\left.4.90 \mathrm{mmol}\right)$, MPDL (0.5296 g, $3.27 \mathrm{mmol}$ ), Gem-AMA-SG1 (205.0 mg, $3.35 \times$ $\left.10^{-1} \mathrm{mmol}\right)$, SG1 (12 mg, $\left.3.51 \times 10^{-2} \mathrm{mmol}\right)$ and anhydrous toluene $(2.0 \mathrm{~g}, 2.31 \mathrm{~mL})]$ and $\mathbf{P 3}\left(f_{\text {MPDL }, 0}=0.7\right)$ [OEGMA (0.8862 g, $2.95 \mathrm{mmol})$, MPDL (1.1138 g, $6.88 \mathrm{mmol})$, Gem-AMASG1 (65.0 mg, $\left.1.06 \times 10^{-1} \mathrm{mmol}\right)$, SG1 $(3.6 \mathrm{mg}, 1.05 \times$ $\left.10^{-2} \mathrm{mmol}\right)$ and anhydrous toluene $\left.(2.0 \mathrm{~g}, 2.31 \mathrm{~mL})\right]$. The final composition of the prodrug was determined by comparing the methoxy protons of OEG from OEGMA (at $3.4 \mathrm{ppm}$ ) to the aromatic protons of MPDL (at $7.2 \mathrm{ppm}$ ). The presence of Gem was quantitatively confirmed by ${ }^{19} \mathrm{~F}$ NMR by comparing the integration of the fluorine atoms of the internal standard PFCE $(\delta=-88 \mathrm{ppm})$ and of $\operatorname{Gem}(\delta=-117 \mathrm{ppm})$. Copolymers with lower targeted $M_{\mathrm{n}}$ were prepared (Table $\mathrm{S} 1 \dagger$ ) by following a similar procedure to that of P3: P3' (targeted $M_{\mathrm{n}}=9000 \mathrm{~g}$ $\mathrm{mol}^{-1}, f_{\text {MPDL }, 0}=0.7$ ) [OEGMA (0.8955 g, $2.99 \mathrm{mmol}$ ), MPDL (1.113 g, $6.87 \mathrm{mmol})$, Gem-AMA-SG1 (65.9 mg, $0.11 \mathrm{mmol})$, SG1 $\left(4.1 \mathrm{mg}, 1.20 \times 10^{-2} \mathrm{mmol}\right)$ and anhydrous toluene $(2.0 \mathrm{~g}$, $2.31 \mathrm{~mL})]$ and $\mathbf{P 3}^{\prime \prime}$ (targeted $M_{\mathrm{n}}=3500 \mathrm{~g} \mathrm{~mol}^{-1}, f_{\text {MPDL }, 0}=0.7$ ) [OEGMA (0.9328 g, $3.11 \mathrm{mmol}$ ), MPDL (1.205 g, $7.44 \mathrm{mmol})$, Gem-AMA-SG1 (187.8 mg, $0.31 \mathrm{mmol})$, SG1 (9.7 mg, $2.84 \times 10^{-2}$ $\mathrm{mmol})$ and anhydrous toluene $(2.0 \mathrm{~g}, 2.31 \mathrm{~mL})]$.

Synthesis of low molar mass Gem-digly-poly[(oligo(ethylene glycol) methyl ether methacrylate)-co-(2-methylene-4-phenyl1,3-dioxolane)] (Gem-digly-P(OEGMA-co-MPDL)). Copolymers with a targeted $M_{\mathrm{n}}$ of $\sim 10000 \mathrm{~g} \mathrm{~mol}^{-1}$ were prepared by following a similar procedure to that of expt 1 but with a polymerization time of $8 \mathrm{~h}$. Experimental conditions were as follows: P1d $\left(f_{\text {MPDL }, 0}=0.2\right.$ ) [OEGMA (0.8805 g, $2.93 \mathrm{mmol}$ ), MPDL (0.1195 g, $0.74 \mathrm{mmol}$ ), Gem-digly-AMA-SG1 (266.6 mg, $\left.2.66 \times 10^{-1} \mathrm{mmol}\right)$, SG1 $\left(9 \mathrm{mg}, 2.63 \times 10^{-2} \mathrm{mmol}\right)$ and toluene 
$(1.0 \mathrm{~g}, 1.15 \mathrm{~mL})]$, for P2d $\left(f_{\mathrm{MPDL}, 0}=0.4\right)$ [OEGMA $(0.7375 \mathrm{~g}, 2.46$ $\mathrm{mmol})$, MPDL (0.2660 g, $1.64 \mathrm{mmol})$, Gem-digly-AMA-SG1 $\left(93.3 \mathrm{mg}, 9.32 \times 10^{-2} \mathrm{mmol}\right)$, SG1 $\left(3.2 \mathrm{mg}, 9.36 \times 10^{-3}\right.$ $\mathrm{mmol})$ and toluene $(1.0 \mathrm{~g}, 1.15 \mathrm{~mL})]$ and for P3d $\left(f_{\text {MPDL }, 0}=0.7\right)$ [OEGMA (0.4420 g, $1.47 \mathrm{mmol})$, MPDL (0.5580 g, $3.44 \mathrm{mmol})$, Gem-digly-AMA-SG1 $\left(53.3 \mathrm{mg}, 5.33 \times 10^{-2} \mathrm{mmol}\right)$, SG1 $(1.7 \mathrm{mg}$, $\left.4.89 \times 10^{-3} \mathrm{mmol}\right)$ and toluene $\left.(1.0 \mathrm{~g}, 1.15 \mathrm{~mL})\right]$. The final composition of the prodrug was determined by comparing the methoxy protons of OEG from OEGMA (at $3.4 \mathrm{ppm}$ ) with the aromatic protons of MPDL (at $7.2 \mathrm{ppm}$ ). The presence of Gem was quantitatively confirmed by ${ }^{19} \mathrm{~F}$ NMR by comparing the integration of the fluorine atoms of the internal standard PFCE $(\delta=-88 \mathrm{ppm})$ and of $\operatorname{Gem}(\delta=-117 \mathrm{ppm})$.

Synthesis of low molar mass Gem-poly[(oligo(ethylene glycol) methyl ether methacrylate)-co-styrene] (Gem-P(OEGMAco-S)). Polymer prodrugs without MPDL with a targeted $M_{\mathrm{n}}$ of $\sim 10000 \mathrm{~g} \mathrm{~mol}^{-1}$ were prepared by following a similar procedure to that of expt 1 but with a polymerization time of $8 \mathrm{~h}$. Experimental conditions were as follows: OEGMA (1.4436 g, $4.81 \mathrm{mmol}), \mathrm{S}\left(0.0563 \mathrm{~g}, 5.41 \times 10^{-1} \mathrm{mmol}\right)$, Gem-AMA-SG1 (7.0 mg, $\left.1.14 \times 10^{-1} \mathrm{mmol}\right)$, and anhydrous toluene $(1.5 \mathrm{~g}$, $1.73 \mathrm{~mL}$ ). SEC: $M_{\mathrm{n}}=10300 \mathrm{~g} \mathrm{~mol}^{-1}, M_{\mathrm{w}} / M_{\mathrm{n}}=1.29$.

Synthesis of low molar mass poly[(oligo(ethylene glycol) methyl ether methacrylate)-co-(2-methylene-4-phenyl-1,3dioxolane)] (P(OEGMA-co-MPDL)). Copolymers without Gem P7 with a targeted $M_{\mathrm{n}}$ of $\sim 10000 \mathrm{~g} \mathrm{~mol}^{-1}$ and $f_{\mathrm{MPDL}, 0}=0.4$ were prepared by following a similar procedure to that of expt 1 but with a polymerization time of $8 \mathrm{~h}$. Experimental conditions were as follows: OEGMA (1.1028 g, $3.68 \mathrm{mmol})$, MPDL (0.3972 g, $2.45 \mathrm{mmol})$, BlocBuilder MA (15.0 mg, $\left.3.94 \times 10^{-2} \mathrm{mmol}\right)$, and anhydrous toluene $(1.5 \mathrm{~g}, 1.73 \mathrm{~mL})$. The final composition of the copolymer was determined by comparing the terminal methoxy protons of pendant OEG for OEGMA (at $3.4 \mathrm{ppm}$ ) with the aromatic protons of MPDL (at $7.2 \mathrm{ppm}$ ). SEC: $M_{\mathrm{n}}=12100 \mathrm{~g}$ $\mathrm{mol}^{-1}, M_{\mathrm{w}} / M_{\mathrm{n}}=1.30 .{ }^{1} \mathrm{H}$ NMR: $F_{\mathrm{MPDL}}=0.13$.

Synthesis of low molar mass Gem-poly[(methyl methacrylate)-co-(2-methylene-4-phenyl-1,3-dioxolane)] (Gem-P(MMA-coMPDL)). Copolymers with a targeted $M_{\mathrm{n}}$ of $\sim 10000 \mathrm{~g} \mathrm{~mol}^{-1}$ were prepared by following a similar procedure to that of expt 4 but with a polymerization time of $5 \mathrm{~h}$. Experimental conditions were as follows: P4 $\left(f_{\text {MPDL }, 0}=0.2\right)$ [MMA $(1.0673 \mathrm{~g}, 10.67 \mathrm{mmol})$, MPDL (0.4327 g, $2.67 \mathrm{mmol}$ ), Gem-AMA-SG1 (340.0 mg, $5.56 \times$ $\left.10^{-1} \mathrm{mmol}\right)$, SG1 $\left(18.1 \mathrm{mg}, 5.29 \times 10^{-2} \mathrm{mmol}\right)$ and anhydrous toluene $(1.5 \mathrm{~g}, 1.73 \mathrm{~mL})]$, for P5 $\left(f_{\mathrm{MPDL}, 0}=0.4\right)$ [MMA $(0.7215 \mathrm{~g}$, $7.22 \mathrm{mmol})$, MPDL (0.7785 g, $4.81 \mathrm{mmol})$, Gem-AMA-SG1 $\left(230 \mathrm{mg}, 3.76 \times 10^{-1} \mathrm{mmol}\right)$, SG1 $\left(12.3 \mathrm{mg}, 3.60 \times 10^{-2}\right.$ $\mathrm{mmol})$ and anhydrous toluene $(1.5 \mathrm{~g}, 1.73 \mathrm{~mL})]$ and for $\mathbf{P 6}$ $\left(f_{\mathrm{MPDL}, 0}=0.7\right)[\mathrm{MMA}(0.3135 \mathrm{~g}, 3.14 \mathrm{mmol})$, MPDL (1.1865 g, $7.32 \mathrm{mmol})$, Gem-AMA-SG1 $\left(30.0 \mathrm{mg}, 4.90 \times 10^{-2} \mathrm{mmol}\right), \mathrm{SG} 1$ $\left(1.6 \mathrm{mg}, 4.69 \times 10^{-3} \mathrm{mmol}\right)$ and anhydrous toluene $(1.5 \mathrm{~g}$, $1.73 \mathrm{~mL})]$. The final composition of the prodrug was determined by comparing the methyl protons in the $\alpha$-position to the ester group of MMA (at $3.7 \mathrm{ppm}$ ) with the aromatic protons of MPDL (at $7.2 \mathrm{ppm}$ ). The presence of Gem was quantitatively confirmed by ${ }^{19} \mathrm{~F}$ NMR by comparing the integration of the fluorine atoms of the internal standard $\operatorname{PFCE}(\delta=-88 \mathrm{ppm})$ and of Gem $(\delta=-117 \mathrm{ppm})$.
Synthesis of low molar mass Gem-digly-poly(methyl methacrylate)-co-(2-methylene-4-phenyl-1,3-dioxolane) (Gem-diglyP(MMA-co-MPDL)). Copolymers with a targeted $M_{\mathrm{n}}$ of $\sim 10000 \mathrm{~g} \mathrm{~mol}^{-1}$ were prepared by following a similar procedure to that of expt 4 but with a polymerization time of $5 \mathrm{~h}$. Experimental conditions were as follows: P4d $\left(f_{\text {MPDL }, 0}=0.2\right)$ [MMA (1.0673 g, $10.67 \mathrm{mmol}$ ), MPDL (0.4327 g, $2.67 \mathrm{mmol}$ ), Gem-digly-AMA-SG1 $\left(152.0 \mathrm{mg}, 1.52 \times 10^{-1} \mathrm{mmol}\right), \quad$ SG1 $\left(5.2 \mathrm{mg}, 1.52 \times 10^{-2} \mathrm{mmol}\right)$ and anhydrous toluene $(1.5 \mathrm{~g}$, $1.73 \mathrm{~mL})]$ for P5d $\left(f_{\text {MPDL }, 0}=0.4\right)[\mathrm{MMA}(0.7215 \mathrm{~g}, 7.22 \mathrm{mmol})$, MPDL (0.7785 g, $4.81 \mathrm{mmol})$, Gem-digly-AMA-SG1 (100.0 mg, $\left.9.99 \times 10^{-2} \mathrm{mmol}\right)$, SG1 $\left(3.4 \mathrm{mg}, 9.95 \times 10^{-3} \mathrm{mmol}\right)$ and anhydrous toluene $(1.5 \mathrm{~g}, 1.73 \mathrm{~mL})]$ and for P6d $\left(f_{\text {MPDL }, 0}=0.7\right)$ [MMA (0.3135 g, $3.14 \mathrm{mmol})$, MPDL (1.1865 g, $7.32 \mathrm{mmol})$, Gemdigly-AMA-SG1 (25 mg, $\left.2.50 \times 10^{-2} \mathrm{mmol}\right)$, SG1 $(0.9 \mathrm{mg}, 2.63 \times$ $\left.10^{-3} \mathrm{mmol}\right)$ and anhydrous toluene $\left.(1.5 \mathrm{~g}, 1.73 \mathrm{~mL})\right]$. The final composition of the prodrug was determined by comparing the methyl protons in the $\alpha$-position to the ester group of MMA (at 3.7 ppm) to the aromatic protons of MPDL (at $7.2 \mathrm{ppm}$ ). The presence of Gem was quantitatively confirmed by ${ }^{19} \mathrm{~F}$ NMR by comparing the integration of the fluorine atoms of the internal standard PFCE $(\delta=-88 \mathrm{ppm})$ and of Gem $(\delta=-117 \mathrm{ppm})$.

Synthesis of low molar mass Gem-poly[(methyl methacrylate)-co-styrene] (Gem-P(MMA-co-S)). Polymer prodrugs without MPDL with a targeted $M_{\mathrm{n}}$ of $\sim 10000 \mathrm{~g} \mathrm{~mol}^{-1}$ were prepared by following a similar procedure to that of expt 4 but with a polymerization time of $5 \mathrm{~h}$. Experimental conditions were as follows: MMA (1.3393 g, $13.39 \mathrm{mmol}), \mathrm{S}(0.1607 \mathrm{~g}, 15.45 \mathrm{mmol}$ ), Gem-AMA-SG1 $\left(2.81 \mathrm{mg}, 4.59 \times 10^{-2} \mathrm{mmol}\right)$, and anhydrous toluene (1.5 g, $1.73 \mathrm{~mL})$. SEC: $M_{\mathrm{n}}=9751 \mathrm{~g} \mathrm{~mol}^{-1}, M_{\mathrm{w}} / M_{\mathrm{n}}=1.33$.

Synthesis of low molar mass poly[(methyl methacrylate)co-(2-methylene-4-phenyl-1,3-dioxolane)] (P(MMA-co-MPDL)). Copolymers without Gem P8 with a targeted $M_{\mathrm{n}}$ of $\sim 10000 \mathrm{~g}$ $\mathrm{mol}^{-1}$ and $f_{\text {MPDL }, 0}=0.7$ were prepared by following a similar procedure to that of expt 4 but with a polymerization time of $5 \mathrm{~h}$. Experimental conditions were as follows: MMA (0.3604 g, $3.60 \mathrm{mmol})$, MPDL (0.4010 g, $2.47 \mathrm{mmol})$, BlocBuilder MA $\left(16.0 \mathrm{mg}, 4.20 \times 10^{-2} \mathrm{mmol}\right)$, and anhydrous toluene $(0.77 \mathrm{~g}$, $0.89 \mathrm{~mL})$. The final composition of the copolymer was determined by comparing the methyl protons in the $\alpha$-position to the ester group of MMA (at $3.7 \mathrm{ppm}$ ) to the aromatic protons of MPDL (at $7.2 \mathrm{ppm}$ ). SEC: $M_{\mathrm{n}}=9100 \mathrm{~g} \mathrm{~mol}^{-1}, M_{\mathrm{w}} / M_{\mathrm{n}}=1.26 .{ }^{1} \mathrm{H}$ NMR: $F_{\text {MPDL }}=0.17$.

\section{Deprotection of the copolymers}

Deprotection of Gem-digly-P(OEGMA-co-MPDL). The TBDMS-protected Gem-digly-P(OEGMA-co-MPDL) copolymer (100 mg) was dissolved in $0.5 \mathrm{~mL}$ THF and TBAF ( $1 \mathrm{M}$ in THF, $50 \mu \mathrm{L}$ ) was added. The solution was allowed to stir for $30 \mathrm{~min}$ and the solvent was removed under reduced pressure. After solubilization in $2 \mathrm{~mL}$ of DCM, the organic phase was washed twice with brine, precipitated in a mixture of cold cyclohexane/petroleum ether $(1 / 1, v / v)$ and dried under reduced pressure. The copolymers were analyzed by ${ }^{1} \mathrm{H}$ NMR and SEC. NMR analysis showed complete disappearance of TBDMS protecting groups (Fig. S2 $\dagger$ ) and ${ }^{19} \mathrm{~F}$ NMR confirmed the quantitative presence of Gem. 
Deprotection of Gem-digly-P(MMA-co-MPDL). The TBDMSprotected copolymer Gem-digly-P(MMA-co-MPDL) (100 mg) was dissolved in $0.5 \mathrm{~mL}$ THF and TBAF $(1 \mathrm{M}$ in THF, $50 \mu \mathrm{L})$ was added. The solution was allowed to stir for $30 \mathrm{~min}$ before pouring into $10 \mathrm{~mL}$ of $\mathrm{MeOH}$. The copolymer was then precipitated using cold $\mathrm{MeOH}$ and dried under high vacuum. Polymers were analyzed by ${ }^{1} \mathrm{H}$ NMR and SEC. NMR analysis showed complete disappearance of TBDMS protecting groups (Fig. $\mathrm{S} 3 \dagger$ ) and ${ }^{19} \mathrm{~F}$ NMR confirmed the quantitative presence of Gem.

\section{Hydrolytic degradation}

Hydrolytic degradation of Gem-P(OEGMA-co-MPDL). In a $5 \mathrm{~mL}$ vial, $50 \mathrm{mg}$ of copolymer was dissolved in $5 \mathrm{~mL}$ of $5 \%$ $\mathrm{KOH}$ aqueous solution and stirred at room temperature. Samples $(1 \mathrm{~mL})$ were periodically taken, neutralized with $1 \mathrm{M}$ $\mathrm{HCl}$ aqueous solution and lyophilized. $2 \mathrm{~mL}$ of chloroform was then added, allowing filtration of the salts. Finally, the solvent was removed under reduced pressure and the degradation products were analyzed by SEC.

Hydrolytic degradation of Gem-P(MMA-co-MPDL). In a $5 \mathrm{~mL}$ vial, $50 \mathrm{mg}$ of copolymer was dissolved in $2.5 \mathrm{~mL}$ of THF. After solubilization, $2.5 \mathrm{~mL}$ of potassium hydroxide solution $(\mathrm{KOH}$, $10 \%$ ) in methanol was added. The cloudy mixture was stirred at room temperature. Samples $(1 \mathrm{~mL})$ were periodically taken, immediately dried under vacuum and $2 \mathrm{~mL}$ of chloroform was added, allowing filtration of the salts. Finally, the solvent was removed under reduced pressure and the degradation products were analyzed by SEC. Note that the carboxylic acid chain ends after degradation can be responsible for aggregation of polymer chains during SEC analysis, resulting in larger apparent $M_{\mathrm{n}}$. This problem was resolved by adding $0.1 \%(\mathrm{w} / \mathrm{w})$ of TFA in both the eluent and the sample.

\section{Nanoparticle preparation}

Nanoparticles were prepared by the nanoprecipitation technique. ${ }^{55}$ For Gem-P(MMA-co-MPDL) and Gem-digly-P(MMA-coMPDL), $2 \mathrm{mg}$ of copolymer was dissolved in $2 \mathrm{~mL}$ of THF, and added dropwise to $4 \mathrm{~mL}$ MilliQ water under stirring. For Gem-P(OEGMA-co-MPDL) and Gem-digly-P(OEGMA-co-MPDL), $2.5 \mathrm{mg}$ of copolymer was dissolved in $0.5 \mathrm{~mL}$ of THF, and added dropwise to $1 \mathrm{~mL}$ MilliQ water under stirring. In all cases, THF was evaporated at ambient temperature using a Rotavapor. Average diameter $\left(D_{z}\right)$ and zeta potential $(\zeta)$ measurements were carried out in triplicate. For stability studies, the different samples were either dropped in water or PBS, or diluted in complete cell culture medium to reach a final concentration of $0.25 \mathrm{mg} \mathrm{mL}^{-1}$. Samples were kept at $4{ }^{\circ} \mathrm{C}$ and allowed to warm to room temperature before each measurement which was performed in triplicate at $25{ }^{\circ} \mathrm{C}$.

\section{Nanoprecipitation yield}

The amount of Gem-P(OEGMA-co-MPDL) nanoparticles formed by nanoprecipitation was determined as follows. A minimal amount of $4 \mathrm{~mL}$ of nanoparticle suspension (corresponding at least to $10 \mathrm{mg}$ of copolymer) was ultracentrifuged (40 $000 \mathrm{rpm}$,
$4 \mathrm{~h}, 4{ }^{\circ} \mathrm{C}$ ). The supernatant and the pellet were separated and freeze-dried. The weight fraction of nanoparticles formed after nanoprecipitation was calculated according to: $w_{\text {nanoparticles }}=$ $m_{\text {pellet }} /\left(m_{\text {pellet }}+m_{\text {supernantant }}\right)$.

\section{Drug release kinetics}

To determine the release kinetics of Gem, $1.5 \mathrm{~mL}$ of Gem-P(OEGMA-co-MPDL) P1-P3 and P1d-P3d $\left(0.5 \mathrm{mg} \mathrm{mL}^{-1}\right)$ or Gem-P(MMA-co-MPDL) P4-P6 and P4d-P6d (0.5 $\left.\mathrm{mg} \mathrm{mL} \mathrm{mL}^{-1}\right)$ nanoparticles were added to $1.5 \mathrm{~mL}$ of human serum solution supplemented with $200 \mu \mathrm{g} \mathrm{mL}{ }^{-1}$ tetrahydrouridine (THU). ${ }^{56,57}$ The mixture was incubated at $37{ }^{\circ} \mathrm{C}$ and aliquots $(600 \mu \mathrm{L})$ of incubation medium were withdrawn at different time points (1, 4, 8 and $24 \mathrm{~h}$ ), spiked with $60 \mu \mathrm{L}$ of $10 \mu \mathrm{M}$ theophylline (Internal Standard, IS) before addition of $1 \mathrm{~mL}$ of a mixture of acetonitrile/methanol (90/10, v/v) and ultracentrifuged (15 $000 \mathrm{~g}, 20 \mathrm{~min}, 4^{\circ} \mathrm{C}$ ). The supernatant was then evaporated to dryness under a nitrogen flow at $30^{\circ} \mathrm{C}$. The released native drug was quantified by reverse-phase HPLC (Waters, Milford, MA 01757, USA) with a C18 column. To ensure that only native Gem was quantified, the calibration curve was carried out using native Gem (elution time $=10.6 \mathrm{~min}$ ). For drug-release experiments, only this peak was integrated to determine native Gem content. Briefly, the chromatographic system consisted of a Waters 1525 Binary HPLC pump, a Waters 2707 Autosampler, a C18 Uptisphere column $(3 \mu \mathrm{m}, 150 \times 4.6 \mathrm{~mm}$; Interchim), HPLC column temperature controllers (model 7950 column heater and chiller; Jones Chromatography, Lakewood, CO), and a Waters 2998 programmable photodiode-array detector. The HPLC column was maintained at $30{ }^{\circ} \mathrm{C}$ and detection was monitored at $270 \mathrm{~nm}$. The HPLC mobile phase consisted of a mixture of methanol and water with $0.05 \mathrm{M}$ sodium acetate (pH 5.0, eluent A: 5/95, v/v; eluent B 97/3, v/v). The residues were dissolved in $100 \mu \mathrm{L}$ of eluent A. Elution was performed at a flow rate of $0.8 \mathrm{~mL} \mathrm{~min}{ }^{-1}$ isocratically for $8 \mathrm{~min}$ with eluent A followed by a linear gradient $(1 \mathrm{~min}$ ) to $100 \%$ eluent $\mathrm{B}$. This was followed by a $15 \mathrm{~min}$ hold at eluent B and a 1 min linear gradient back to $100 \%$ eluent A. The system was held for $6 \mathrm{~min}$ for equilibration back to initial conditions.

\section{Biological evaluation}

Cell lines and cell culture. Human pancreatic cancer cell line MiaPaCa-2 and human lung carcinoma cell line A549 were obtained from the American Type Culture Collection. All cell lines were maintained as recommended. Briefly, A549 and MiaPaCa-2 cells were grown in Dulbecco's minimal essential medium (DMEM). All media were supplemented with $10 \%$ heatinactivated FBS $\left(56{ }^{\circ} \mathrm{C}, 30 \mathrm{~min}\right)$, penicillin $\left(100 \mathrm{U} \mathrm{mL}^{-1}\right)$ and streptomycin $\left(100 \mu \mathrm{g} \mathrm{mL} \mathrm{m}^{-1}\right)$. Medium for MiaPaCa-2 cell line was supplemented with $2.5 \%$ heat-inactivated $\left(56{ }^{\circ} \mathrm{C}, 30 \mathrm{~min}\right)$ horse serum (Gibco). Cells were maintained in a humid atmosphere at $37{ }^{\circ} \mathrm{C}$ with $5 \% \mathrm{CO}_{2}$.

In vitro anticancer activity. MTT [3-(4,5-dimethylthiazol-2-yl)2,5-diphenyl tetrazolium bromide] was used to evaluate the cytotoxicity of the different polymer prodrugs. Briefly, cells $(5 \times$ $10^{3}$ per well) were seeded in 96-well plates. After overnight 
incubation, the cells were then exposed to a series of concentrations of polymer prodrugs, control polymers or free Gem for $72 \mathrm{~h}$ (A549 cells) or $120 \mathrm{~h}$ (MiaPaCa-2 cells). $20 \mu \mathrm{L}$ of MTT solution ( $5 \mathrm{mg} \mathrm{mL}^{-1}$ in PBS) was then added to each well. The plates were incubated for $1 \mathrm{~h}$ at $37{ }^{\circ} \mathrm{C}$ and the medium was removed. $200 \mu \mathrm{L}$ of DMSO was then added to each well to dissolve the precipitates. Absorbance was measured at $570 \mathrm{~nm}$ using a plate reader (Metertech $\Sigma 960$, Fisher Bioblock, Illkirch, France). The percentage of surviving cells was calculated as the absorbance ratio of treated to untreated cells. The inhibitory concentration $50 \%\left(\mathrm{IC}_{50}\right)$ of the treatments was determined from the dose-response curve. All experiments were set up in sextuplicate to determine means and SDs.

\section{Results and discussion}

\section{Synthetic strategy}

To illustrate our approach, gemcitabine (Gem, 2'-deoxy-2',2'difluorocytidine) was selected as an anticancer drug. Gem is a nucleoside analog approved for the treatment of various solid tumors including lung, pancreatic, breast, or ovarian cancers. ${ }^{58}$ However, severe limitations restrict its clinical use and drastically reduce its efficacy: (i) short plasma half-life and rapid renal excretion due to rapid deamination by deoxycitidine deaminase, (ii) induction of resistances owing to inhibition of transmembrane transporter nucleoside, and (iii) severe side effects as a result of frequent administration schedule. Therefore, new prodrug strategies applied to Gem are of high importance in the field of nanomedicine.

This new class of polymer prodrugs was synthesized by nitroxide-mediated radical ring-opening copolymerization (NMrROP) between a methacrylic ester and 2-methylene-4phenyl-1,3-dioxolane (MPDL) as a CKA, from a Gemfunctionalized alkoxyamine initiator (Fig. 1). This synthetic pathway was built upon our previous findings showing that MPDL, a 5-membered ring CKA, is a very attractive monomer that can be easily obtained and efficiently incorporated into a polymethacrylate backbone by NMrROP, resulting in welldefined copolymers with controllable level of ester group insertion and up to nearly complete degradation upon hydrolysis..$^{\text {54,59-61 }}$

To establish structure-activity relationships and obtain polymer prodrugs with the highest activity against cancer cells, various structural parameters were varied such as the nature of the methacrylic ester, the composition of the copolymer and the nature of the drug-copolymer linker (Fig. 2). More specifically, two different methacrylic ester monomers were copolymerized with MPDL: either oligo(ethylene glycol) methyl ether methacrylate (OEGMA) as a hydrophilic monomer or methyl methacrylate (MMA) as a hydrophobic one (Fig. 2a and c). Copolymerizations were initiated by two different alkoxyamines based on the SG1 nitroxide, which only differed in the nature of the linker between Gem and the alkoxyamine moiety: an amide bond (Gem-AMA-SG1) or an amide bond connected to a labile diglycolate linker (Gem-digly-AMA-SG1) (Fig. 2b). Variable initial amounts of MPDL were also investigated to confer the resulting polymer prodrugs with distinct levels of degradability.

\section{Synthesis of Gem-based alkoxyamine initiators}

Given its susceptibility to deamination, ${ }^{62}$ Gem was derivatized through its C-4 amino group. Gem-AMA-SG1 was synthesized by direct coupling between unprotected Gem and AMA-SG1 using PyBOP as a coupling agent. For Gem-digly-AMA-SG1, the best conditions were obtained via protection of the two hydroxyl groups with TBDMSCl, followed by PyBOP-assisted coupling of the resulting TBDMSGem with AMA-digly-SG1 (Fig. 2b). The expected product (Fig. S1 $\dagger$ ) was obtained with a coupling yield of $63 \%$.

\section{Copolymerization kinetics}

A comprehensive kinetic study was first performed to investigate the influence of the different parameters on the control of the copolymerization. Gem-AMA-SG1 or Gem-digly-AMA-SG1 alkoxyamines were used to initiate the NMrROP of OEGMA (expts 1-3 and 1d-3d, Fig. 3) or MMA (expts 4-6 and 4d-6d, Fig. 4) in the presence of variable initial fractions of MPDL $\left(f_{\text {MPDL }, 0}=0.2-0.7\right)$ at $90{ }^{\circ} \mathrm{C}$ in $50 \mathrm{wt} \%$ toluene. In all cases, the higher the initial fraction of MPDL, the better the control of the copolymerization. For $f_{\mathrm{MPDL}, 0}=0.2$, regardless of the methacrylic ester used (expts 1,1d, 4 and $4 \mathrm{~d}$ ), the copolymerizations did not exhibit a first order kinetics while $M_{\mathrm{n}}$ values hardly increased with conversion and were much higher than the theoretical ones with rather high dispersities after 50\% conversion, thus indicating a partial control. Such a low initial amount of MPDL was therefore not sufficient for efficient insertion of MPDL in the copolymer (according to the reactivity ratios) to prevent irreversible termination reactions. For $f_{\text {MPDL }, 0}$ $=0.4$, (expts 2, 2d, 5 and $5 \mathrm{~d}$ ), the control over the polymerization was significantly improved, leading to nearly first order kinetics, linear increase of $M_{\mathrm{n}}$ with conversion, exhibiting values closer to the theoretical ones, and lower dispersities even at high conversion for expts 4-6 and 4d-6d. Control was further enhanced for $f_{\text {MPDL }, 0}=0.7$ (expt 3, 3d, 6 and $6 \mathrm{~d}$ ).

Interestingly, the control was generally better when the copolymerization was initiated by Gem-digly-AMA-SG1 compared to those initiated by Gem-AMA-SG1. $M_{\mathrm{n}}$ values and dispersities at high conversions were indeed systematically lower with Gem-digly-AMA-SG1. This trend can be explained by the structure of the alkoxyamines and its influence on its dissociation rate constant and subsequently on the control of the polymerization. Conversely to Gem-digly-AMA-SG1, GemAMA-SG1 is prone to intramolecular hydrogen-bonding (IHB) between the hydrogen of the amide from the propagating radical and the nitroxide fragment. ${ }^{63}$ It resulted in slower dissociation kinetics and thus a less efficient control because of the lower amount of released nitroxide.

\section{Synthesis of low molar mass polymer prodrugs for biological evaluations}

One of the main benefits of the drug-initiated method is the facile tuning of the drug loading simply by varying the $M_{\mathrm{n}}$ of the polymer, which is of great importance for further biological evaluation. Herein, we targeted lower molar mass polymer 

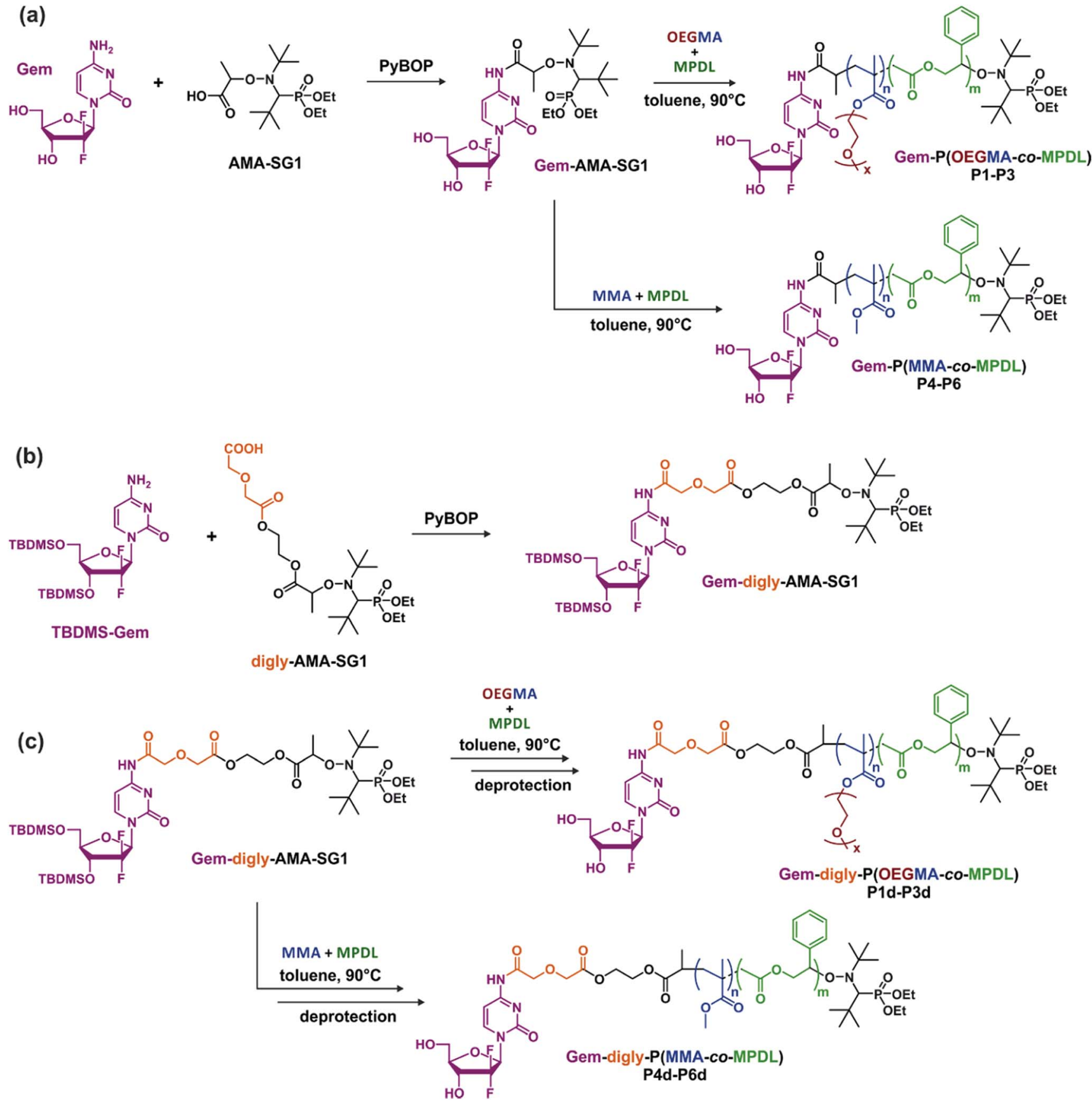

Fig. 2 Synthesis of (a) Gem-P(OEGMA-CO-MPDL) P1-P3 and Gem-P(MMA-Co-MPDL) P4-P6 by NMrROP in toluene at $90{ }^{\circ} \mathrm{C}$, (b) Gem-diglyAMA-SG1 by PyBOP-assisted coupling between TBDMS-Gem and digly-AMA-SG1 and (c) Gem-digly-P(OEGMA-CO-MPDL) P1d-P3d and Gemdigly-P(MMA-CO-MPDL) P4d-P6d by NMrROP in toluene at $90^{\circ} \mathrm{C}$ followed by TBDMS group removal.

prodrugs $\left(M_{\mathrm{n}} \sim 10000 \mathrm{~g} \mathrm{~mol}^{-1}\right)$ to obtain a drug loading of $\sim 2.5 \mathrm{wt} \%$ by adapting the reaction conditions (e.g., lower reaction times and/or lower targeted $M_{\mathrm{n}}$, see the Experimental part). Note that, if needed, higher drug loadings can be successfully obtained (e.g., 3.6 and $9.0 \mathrm{wt} \%)$ by further decreasing the $M_{\mathrm{n}}\left(\mathbf{P} \mathbf{3}^{\prime}\right.$ and $\mathbf{P} 3^{\prime \prime}$, Table S1 $\left.\dagger\right)$. Four libraries of well-defined copolymer prodrugs from each series were prepared (Table 1 and Fig. S4 $\dagger$ ): Gem-P(OEGMA-co-MPDL) (P1P3), Gem-digly-P(OEGMA-co-MPDL) (P1d-P3d), Gem-P(MMA-coMPDL) (P4-P6) and Gem-digly-P(MMA-co-MPDL) (P4d-P6d). A lower reaction time also enabled improving the control by avoiding high monomer conversion and thus extensive occurrence of irreversible termination reactions. Overall, dispersities of the resulting copolymers ranged from 1.1 to 1.4, except for P1 whose control was difficult to achieve given the very low amount of initial MPDL ${ }^{59}$ and the use of the less efficient alkoxyamine (as detailed in the previous section). ${ }^{1} \mathrm{H}$ NMR spectroscopy of the purified copolymers (and deprotected for P1d-P6d) in $\mathrm{CDCl}_{3}$ (Fig. S5-S8 $\dagger$ ) and in DMSO-d ${ }_{6}$ (Fig. S9-S12 $\dagger$ ) showed all signals expected for each structure. ${ }^{19} \mathrm{~F}$ NMR spectroscopy confirmed 
(a)

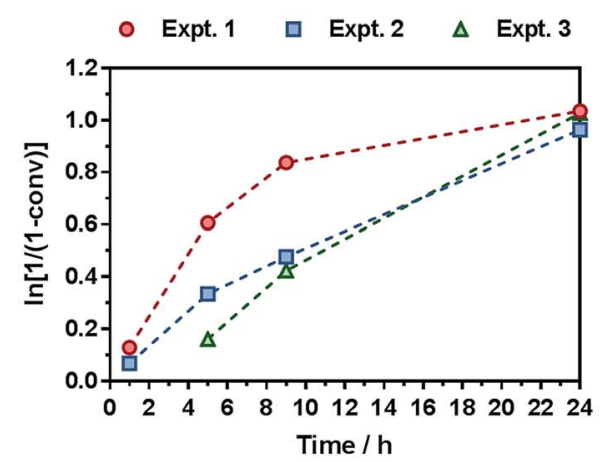

(c)

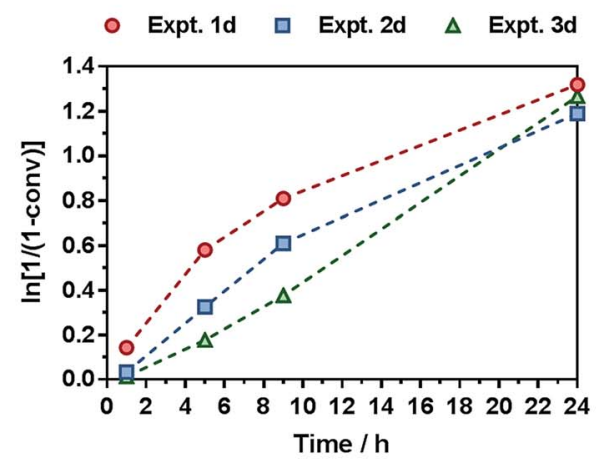

(b)

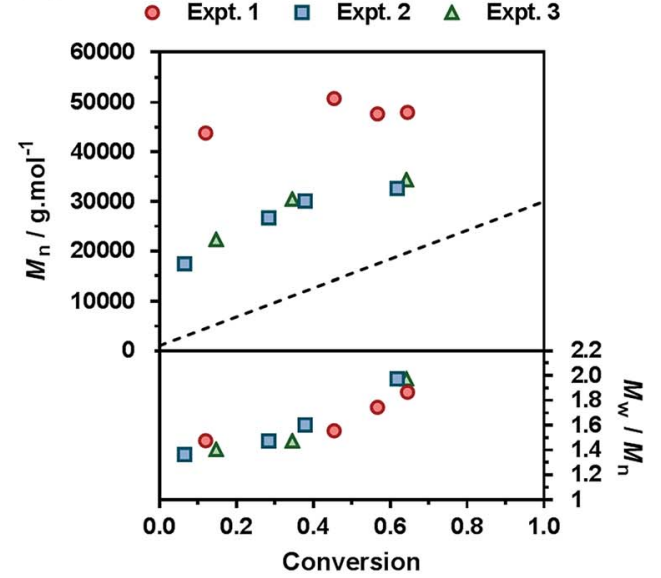

(d)

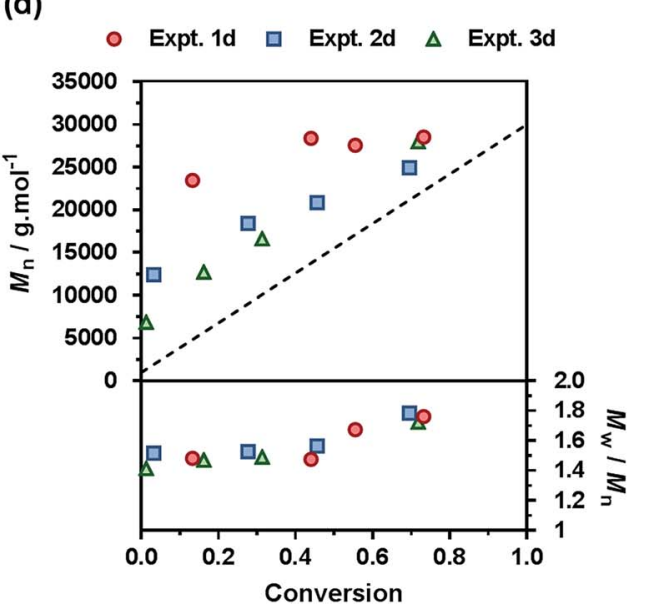

Fig. 3 NMrROP of OEGMA and MPDL in $50 \mathrm{wt} \%$ toluene at $90^{\circ} \mathrm{C}$ as a function of the nature of the alkoxyamine initiator [(a) and (b) Gem-AMASG1, (c) and (d) Gem-digly-AMA-SG1] and the initial fraction of MPDL: $\bullet$ expts 1 and $1 \mathrm{~d}\left(f_{\mathrm{MPDL}, 0}=0.2\right), \boldsymbol{\square}$ expts 2 and $2 \mathrm{~d}\left(f_{\mathrm{MPDL}, 0}=0.4\right), \boldsymbol{\Delta}$ expts 3 and $3 \mathrm{~d}\left(f_{\mathrm{MPDL}, 0}=0.7\right)$. (a) and (c) $\ln [1 /(1-\mathrm{conv})] v s$. time (conv = OEGMA conversion). Dashed lines connecting data points are guides for the eye only. (b) and (d) Number-average molar mass, $M_{n}$ and dispersity, $M_{w} / M_{n}$, vs. conversion. The dashed black line represents the theoretical $M_{n}$.

the quantitative presence of Gem at the extremity of the copolymers.

Despite unfavorable reactivity ratios of the different monomer pairs $\left(r \mathrm{MPDL}=0\right.$ and $r \mathrm{OEGMA}=6.95,{ }^{59}$ and $r \mathrm{MPDL}=$ 0.01 and $r \mathrm{MMA}=4.0$ (ref. 54)), the molar fraction of MPDL in the copolymer $\left(F_{\mathrm{MPDL}}\right)$ was finely tuned by varying the initial molar fraction of MPDL in the comonomer feed (Table 1) to induce different levels of degradability. On average, $F_{\text {MPDL }}$ was $\sim 0.07$ for $f_{\text {MPDL }, 0}=0.2, \sim 0.13$ for $f_{\text {MPDL }, 0}=0.4$ and $\sim 0.26$ for $f_{\mathrm{MPDL}, 0}=0.7$.

\section{Hydrolytic degradation of the prodrugs}

The degradation of the different copolymer prodrugs was then evaluated under accelerated conditions to probe the presence of the ester group in the polymer backbone, that is at room temperature in $5 \% \mathrm{KOH}$, either in water for OEGMA-based copolymers (P1-P3) or in a THF/MeOH $(50: 50, \mathrm{v} / \mathrm{v})$ mixture for MMA-based copolymers (P4-P6). As expected, control copolymers without MPDL $\left(F_{\text {MPDL }}=0\right)$, Gem-P(OEGMA-co-S) and Gem-P(MMA-co-S), did not undergo any degradation as shown by their constant $M_{\mathrm{n}}$ over time. Conversely,
MPDL-containing copolymer prodrugs led to adjustable degradation in direct relationship with their MPDL content, as shown by the shifts of the SEC chromatograms towards lower $M_{\mathrm{n}}$ values (Fig. S13 and $\mathrm{S} 14 \dagger$ ). Whatever the nature of the methacrylic ester, the higher the MPDL content, the greater the degradation. The $M_{\mathrm{n}}$ decrease (Fig. 5) spanned from 10 to $30 \%$ for copolymers with the lowest MPDL contents (P1 and P4) to $\sim 70 \%$ for those with the highest amounts of MPDL (P3 and P6). These results confirmed the significant insertion of open MPDL units in the main chain of the copolymers and the possibility to fine-tune their degradation by adjusting the initial comonomer stoichiometry.

Note that some discrepancy between theoretical $M_{\mathrm{n}}$ after degradation (calculated according to: $1 / F_{\mathrm{MPDL}}-1$ ) and experimental ones may appear because of unfavorable reactivity ratios, as commonly observed with CKA monomers. ${ }^{59}$ Also, molar mass distributions stayed rather low $(D \sim 1.5-1.8)$ after degradation, which is in agreement with a theoretical investigation $^{64}$ showing that stopping at low conversion for the synthesis of the copolymers is key to maintaining a certain homogeneity of the degraded products. 
(a)

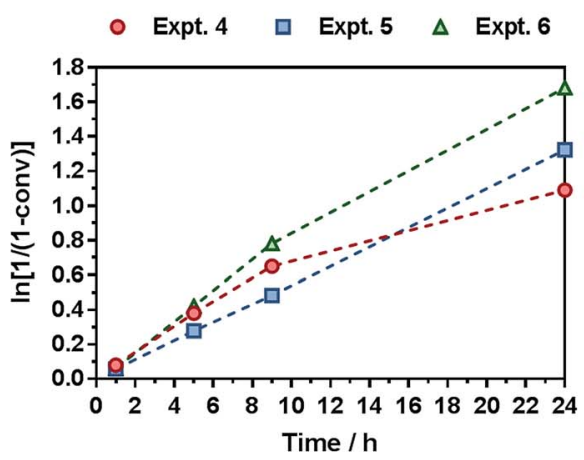

(c)

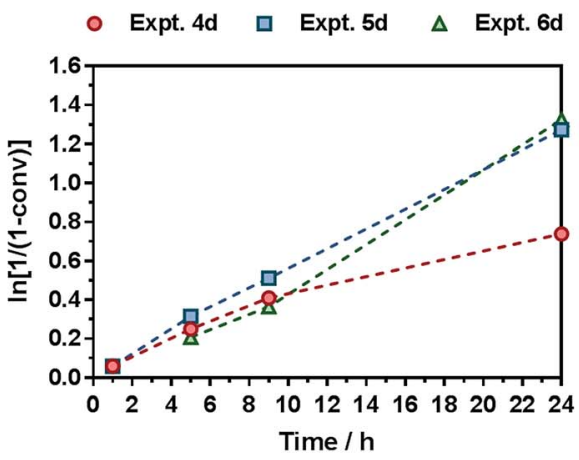

(b)

$\circ$ Expt. 4 Expt. 5 A Expt. 6

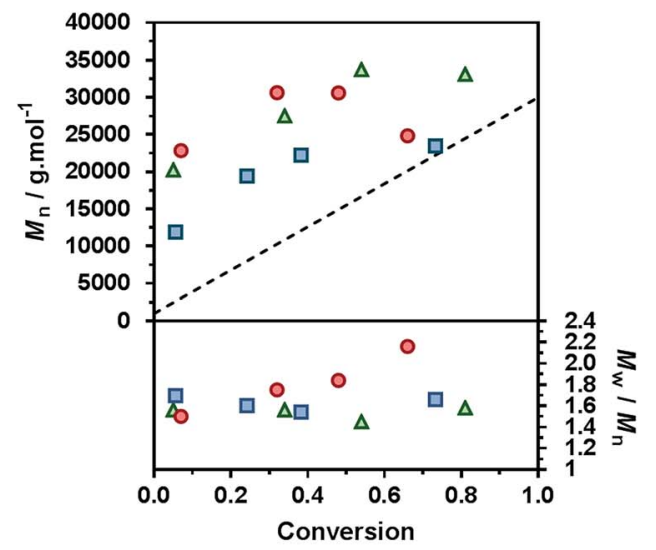

(d)

$\triangle$ Expt. 4d $\square$ Expt. 5d $\Delta$ Expt. 6d

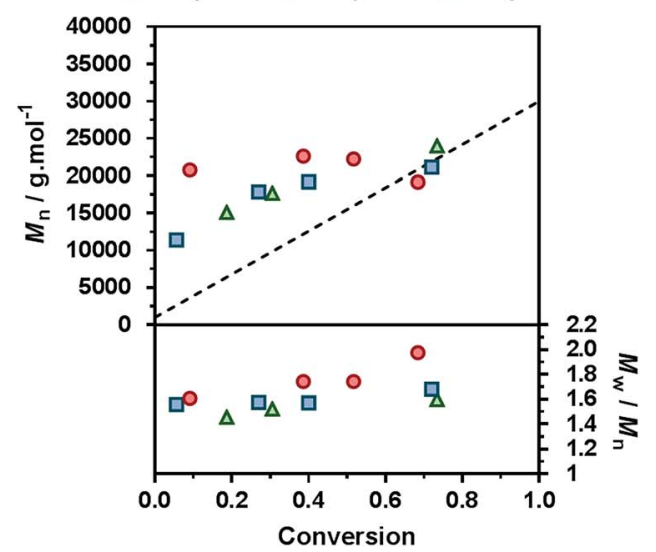

Fig. 4 NMrROP of MMA and MPDL in $50 w t \%$ toluene at $90^{\circ} \mathrm{C}$ as a function of the nature of the alkoxyamine initiator [(a) and (b) Gem-AMA-SG1, (c) and (d) Gem-digly-AMA-SG1] and the initial fraction of MPDL: - expts 4 and $4 d\left(f_{M P D L, 0}=0.2\right), \boldsymbol{\square}$ expts 5 and $5 d\left(f_{M P D L, 0}=0.4\right), \boldsymbol{\Delta}$ expts 6 and $6 \mathrm{~d}\left(f_{\mathrm{MPDL}, 0}=0.7\right)$. (a) and (c) $\ln [1 /(1-\mathrm{conv})] v s$. time (conv = MMA conversion). Dashed lines connecting data points are guides for the eye only. (b) and (d) Number-average molar mass, $M_{n}$ and dispersity, $M_{w} / M_{n}$, vs. conversion. The dashed black line represents the theoretical $M_{n}$.

\section{Physicochemical properties}

Given their hydrophobic backbone and the water-solubility of Gem, Gem-P(MMA-co-MPDL) (P4-P6) and Gem-digly-P(MMA-coMPDL) (P4d-P6d) prodrugs were formulated into nanoparticles in water. They displayed an average diameter in the 109-196 nm range, along with narrow particle size distributions (Table 2) and great colloidal stability in the long run either in water or in cell culture medium (Fig. S15 $\dagger$ ), whereas poor colloidal stability was observed in PBS.

Table 1 Experimental conditions and macromolecular properties of Gem-based P(OEGMA-co-MPDL) and P(MMA-co-MPDL) polymer prodrugs

\begin{tabular}{|c|c|c|c|c|c|c|c|c|}
\hline Prodrug & Alkoxyamine & Methacrylic ester & $f_{\mathrm{MPDL}, 0}$ & Conv. $^{a}(\%) /$ temps (h) & $M_{\mathrm{n}}^{b}\left(\mathrm{~g} \mathrm{~mol}^{-1}\right)$ & Total $D P_{\mathrm{n}}$ & $\Xi^{b}$ & $F_{\mathrm{MPDL}}{ }^{c}$ \\
\hline P1 & Gem-AMA-SG1 & OEGMA & 0.2 & $40 / 8$ & 15500 & 51 & 1.54 & 0.06 \\
\hline $\mathbf{P 2}$ & Gem-AMA-SG1 & OEGMA & 0.4 & $28 / 8$ & 10200 & 34 & 1.39 & 0.12 \\
\hline P3 & Gem-AMA-SG1 & OEGMA & 0.7 & $18 / 8$ & 10000 & 35 & 1.37 & 0.25 \\
\hline P1d & Gem-digly-AMA-SG1 & OEGMA & 0.2 & $61 / 8$ & 11500 & 36 & 1.24 & 0.07 \\
\hline P2d & Gem-digly-AMA-SG1 & OEGMA & 0.4 & $36 / 8$ & 13200 & 43 & 1.24 & 0.11 \\
\hline P3d & Gem-digly-AMA-SG1 & OEGMA & 0.7 & $22 / 8$ & 11200 & 38 & 1.13 & 0.22 \\
\hline $\mathbf{P 4}$ & Gem-AMA-SG1 & MMA & 0.2 & $35 / 5$ & 13200 & 119 & 1.27 & 0.10 \\
\hline P5 & Gem-AMA-SG1 & MMA & 0.4 & $34 / 5$ & 9900 & 83 & 1.28 & 0.19 \\
\hline P6 & Gem-AMA-SG1 & MMA & 0.7 & $23 / 5$ & 10300 & 82 & 1.21 & 0.29 \\
\hline P4d & Gem-digly-AMA-SG1 & MMA & 0.2 & $56 / 8$ & 15400 & 138 & 1.34 & 0.07 \\
\hline P5d & Gem-digly-AMA-SG1 & MMA & 0.4 & $55 / 8$ & 12400 & 106 & 1.29 & 0.12 \\
\hline P6d & Gem-digly-AMA-SG1 & MMA & 0.7 & $33 / 8$ & 10900 & 84 & 1.20 & 0.29 \\
\hline
\end{tabular}

${ }^{a}$ Methacrylic ester conversion determined by ${ }^{1} \mathrm{H}$ NMR. ${ }^{b}$ Determined by SEC after precipitation. ${ }^{c}$ Determined by ${ }^{1} \mathrm{H}$ NMR. 
(a)

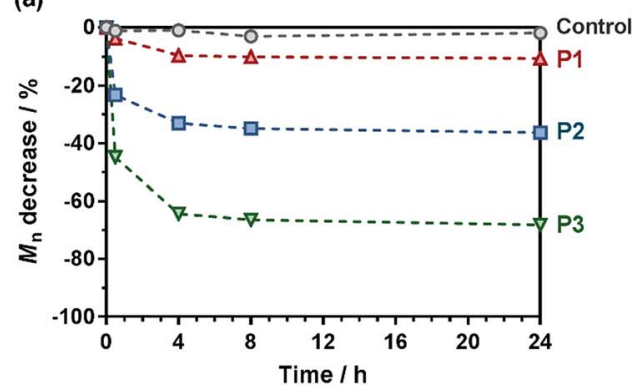

(b)

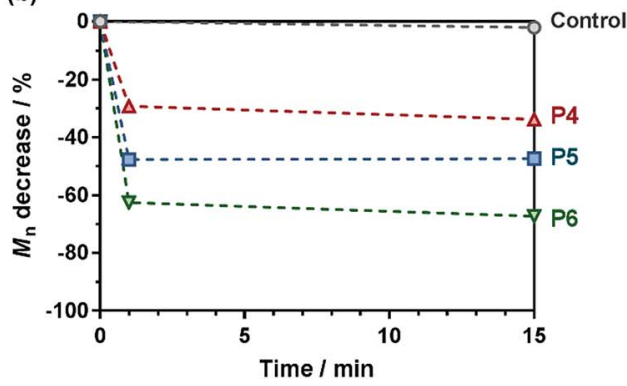

Fig. 5 Hydrolytic degradation under accelerated conditions $(5 \% \mathrm{KOH})$ of the different degradable polymer prodrugs as a function of the MPDL fraction and the nature of the methacrylic ester monomer: (a) Gem-P(OEGMA-co-MPDL); $\boldsymbol{\bullet}$, control $\left(F_{M P D L}=0\right) ; \boldsymbol{\Lambda}, \mathrm{P} 1\left(F_{\mathrm{MPDL}}=0.06\right) ; \mathbf{\square}, \mathrm{P} 2$ $\left(F_{\mathrm{MPDL}}=0.12\right) ; \boldsymbol{\nabla}, \mathrm{P3}\left(F_{\mathrm{MPDL}}=0.25\right)$. (b) Gem-P(MMA-Co-MPDL); $\boldsymbol{0}$, control $\left(F_{\mathrm{MPDL}}=0\right) ; \boldsymbol{\Lambda}, \mathrm{P} 4\left(F_{\mathrm{MPDL}}=0.10\right) ; \boldsymbol{\square}, \mathrm{P} 5\left(F_{\mathrm{MPDL}}=0.19\right) ; \boldsymbol{\nabla}, \mathrm{P} 6$ $\left(F_{M P D L}=0.29\right)$. Dashed lines are guides for the eye only.

Interestingly, nanoparticles prepared from P4d-P6d were significantly smaller than those prepared from P4-P6, possibly because of the additional hydrophilicity provided by the diglycolate linker, promoting Gem positioning at the surface of the nanoparticles and thus inducing a more efficient stabilization. This hypothesis is supported by the increase of the predicted HLB number for a model Gem-digly-PMMA prodrug compared to Gem-PMMA using both the Davies and the Griffin methods (Table S2 $\uparrow$ ). Representative Cryo-TEM images showed spherical morphologies in good agreement with DLS data (Fig. 6a and b and Fig. S16 and S17 $)$ ). All nanoparticles exhibited great colloidal stability over time as shown by their constant size and size distributions for at least 25 days after nanoprecipitation (Fig. 6c). Such an efficient colloidal stability is likely the result of an efficient electrostatic stabilization, as shown by the significantly negative zeta potential measurements (Table 2).

Given the relatively moderate $F_{\text {MPDL }}$ values for P(OEGMA-coMPDL) copolymers, the water-solubility of OEGMA was expected to dominate over the hydrophobicity from MPDL units, and thus preferentially lead to fully water-soluble polymer prodrugs. To validate this hypothesis, Gem-P(OEGMA-co-MPDL) prodrugs with increasing contents of MPDL (P1-P3) were nanoprecipitated in water and the amount of nanoparticles, likely formed by nanoscale aggregation of amphiphilic P(OEGMA-coMPDL) copolymers, was quantified by measurement of the dry content after ultracentrifugation (see the Experimental part and Table S3 $\dagger$ ). The weight fraction of nanoparticles was estimated to be $16 \mathrm{wt} \%$ maximum for the copolymer containing the

Table 2 Characterization of Gem-P(MMA-CO-MPDL) and Gem-diglyP(MMA-Co-MPDL) nanoparticles

\begin{tabular}{lllll}
\hline Prodrug & $D_{\mathrm{z}}{ }^{a}(\mathrm{~nm})$ & $\mathrm{PSD}^{a}$ & $\zeta^{b}(\mathrm{mV})$ & $\% \mathrm{Gem}^{c}(\mathrm{wt} \%)$ \\
\hline P4 & 196 & 0.09 & -55 & 2.0 \\
P5 & 162 & 0.10 & -57 & 2.6 \\
P6 & 174 & 0.09 & -55 & 2.5 \\
P4d & 109 & 0.13 & -37 & 1.7 \\
P5d & 110 & 0.11 & -38 & 2.1 \\
P6d & 117 & 0.10 & -46 & 2.4
\end{tabular}

${ }^{a}$ Determined by DLS. ${ }^{b}$ Zeta potential, determined using the DLS apparatus. ${ }^{c}$ Determined according to: $\% \mathrm{Gem}=M_{\mathrm{w}, \mathrm{Gem}} / M_{\mathrm{n}, \mathrm{SEC}}$. highest amount of MPDL $\left(F_{\mathrm{MPDL}}=0.25\right)$ to less than $1 \mathrm{wt} \%$ for the one with the lowest amount $\left(F_{\mathrm{MPDL}}=0.06\right)$.

\section{Drug release in human serum}

The Gem release kinetics from the two different classes of polymer prodrugs was evaluated in human serum to better mimic the biological environment of the human body compared to accelerated degradation conditions (Fig. 7). In all cases, the maximum drug release was reached after a period of $\sim 1 \mathrm{~h}$ which is rather fast but commonly seen with water-soluble amide prodrugs.$^{65}$ It is also believed that having a hydrophilic drug like Gem promotes fast drug release compared to hydrophobic ones, for instance like paclitaxel, as already observed. ${ }^{12}$ Interestingly, after the maximum drug release is reached, a plateau is observed which likely corresponds to the fraction of drug that is not easily accessible and that cannot be readily cleaved from the copolymers within the time frame of the drug release experiment. We can hypothesize for P(MMA-co-MPDL) nanoparticles that only the surface fraction of Gem is released whereas the fraction which is buried into the nanoparticle's core will be accessible and released only when the nanoparticles are degraded. ${ }^{66}$ As for soluble P(OEGMA-co-MPDL) prodrugs, which are essentially molecularly dissolved even for the highest amounts of MPDL (Fig. S18†), they will form a protective $\mathrm{P}$ (OEGMA-co-MPDL) shroud wrapped around the drug, efficiently protecting the drug-linker moiety from enzymes, similarly to what is observed with PEGylated peptides/proteins. Therefore, only the fraction of Gem located at the periphery of such a PEG-based random coil will be readily cleaved whereas the remaining amount of drug will be accessible after the copolymer gets degraded. ${ }^{66}$

For Gem-P(OEGMA-co-MPDL) P1-P3, the total Gem release gradually increased from $\sim 7$ to $\sim 25 \%$ when decreasing $F_{\mathrm{MPDL}}$ from 0.25 to 0.06 (Fig. 7a). This may be explained by the strong hydrophobic nature of MPDL that prevents enzyme access because of poor solvation of the drug-polymer linker and/or $\pi-$ $\pi$ stacking interactions between MPDL units. Analogous copolymers with the diglycolate linker (P1d-P3d) led to the same trend but with a significantly higher Gem release; from $\sim 33 \%$ for $F_{\mathrm{MPDL}}=0.22$ to $\sim 70 \%$ for $F_{\mathrm{MPDL}}=0.07$ (Fig. $7 \mathrm{~b}$ ), likely because of the increased hydrophilicity and decreased steric 
(a)

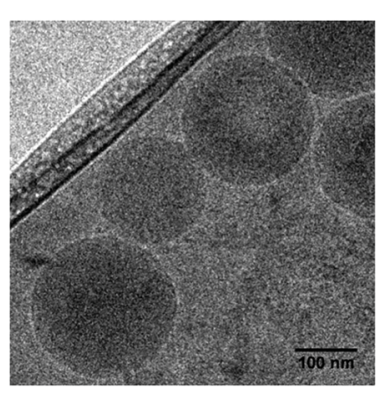

(b)

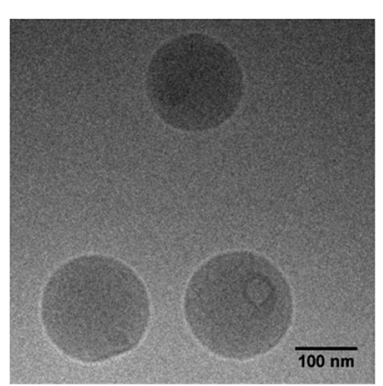


linker - the presence of the diglycolate linker enabled a greater Gem release compared to a simple amide bond and (iii) the hydrophilicity of the methacrylate monomer-OEGMA enabled a greater Gem release compared to MMA. It is therefore suggested that increasing the hydrophilicity in the vicinity of the drug-polymer linkage, by using OEGMA and/or by decreasing the amount of inserted MPDL, which is a strongly hydrophobic monomer, had a beneficial influence on the Gem release. Regarding the diglycolate linker, its beneficial impact may be explained by: (i) its higher lability compared to a single amide bond that may enable its rapid cleavage and (ii) its connection to the amide bond that may promote the amide bond accessibility to enzymes.

\section{In vitro anticancer activity}

A crucial question is whether the above-mentioned drug release trends observed in human serum directly correlate with the anticancer activity of the polymer prodrugs. The cell viability of two cancer cell lines corresponding to clinically relevant cancer models for Gem, human lung carcinoma (A549) and human pancreatic cancer (MiaPaCa-2), was then determined after incubation with the different polymer prodrugs at various concentrations.

Gem-free control copolymers, P(OEGMA-co-MPDL) P7 and $\mathrm{P}(\mathrm{MMA}-\mathrm{co}-\mathrm{MPDL})$ P8, were not cytotoxic for all concentrations tested while free Gem exhibited half maximal inhibitory concentrations $\left(\mathrm{IC}_{50}\right)$ of $4 \mathrm{nM}$ and $14 \mathrm{nM}$ for A549 and MiaPaCa2 cells, respectively. When increasing the MPDL fraction, $\mathrm{IC}_{50}$ values of Gem-P(OEGMA-co-MPDL) P1-P3 increased from 0.30 to $2.14 \mu \mathrm{M}$ for A549 cells and from 0.13 to $1.07 \mu \mathrm{M}$ for MiaPaCa-
2 cells (Fig. 8), which is totally in line with the previously mentioned trends observed from drug release experiments. As expected from drug release experiments, diglycolate-containing polymer prodrugs (P1d-P3d) gave the same trend but were significantly more cytotoxic, leading to $\mathrm{IC}_{50}$ values 5 -8-fold lower for A549 cells (Fig. 8a and b) to 3-4-fold lower for MiaPaCa-2 cells (Fig. 8c and d) compared to those obtained from P1-P3. Note that the small fraction of Gem-P(OEGMA-coMPDL) nanoparticles present along with the soluble Gem$\mathrm{P}(\mathrm{OEGMA}-\mathrm{co}$-MPDL) copolymer did not affect the MTT results as a purified aqueous solution of copolymers $\mathbf{P 2}$ gave the same cytotoxicity profile (Fig. S19†).

Also, in agreement with drug release experiments, GemP(MMA-co-MPDL) P4-P6 and Gem-digly-P(MMA-co-MPDL) P4dP6d polymer prodrug nanoparticles (Fig. 9) were always less cytotoxic than OEGMA-based counterparts. Importantly, whatever the cell line, no decrease in cell viability was observed for P4-P6 even at the highest concentrations, whereas the use of the diglycolate linker made the corresponding prodrugs cytotoxic, especially for those containing less MPDL (P5d and P6d, see Fig. 9b and d). As suggested from drug release experiments, this trend may be correlated with a too high hydrophobicity in the vicinity of the Gem-polymer linker, but also with the nanoparticulate nature of the polymer prodrugs that, conversely to fully water-soluble counterparts, were less accessible to water/enzymes, thus preventing efficient release of Gem (only surface exposed Gem-digly moieties were likely accessible for cleavage). Note that, in general, higher cytotoxicity was observed against MiaPaCa-2 cells, with nearly complete cell death. This is explained by the fact that A549 cells are known to exhibit some (a)

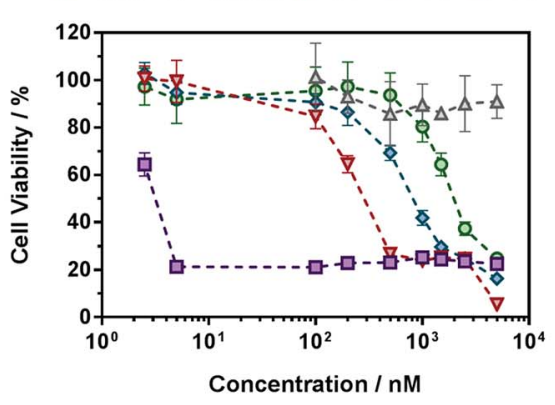

(c)

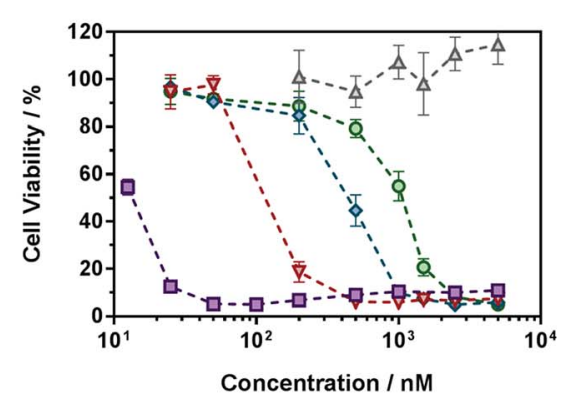

(b)

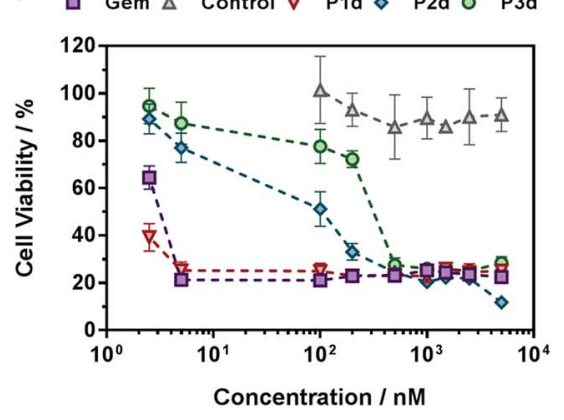

(d)

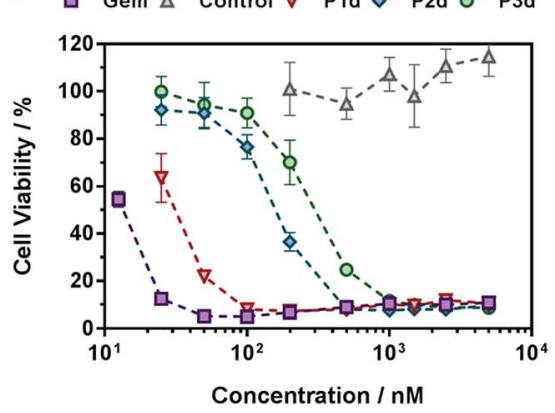

Fig. 8 Cell viability (MTT test) with increasing concentrations of (a and c) Gem, Gem-P(OEGMA-co-MPDL) (P1-P3) and P(OEGMA-co-MPDL) (P7, control) or (b and d) Gem, Gem-digly-P(OEGMA-co-MPDL) (P1d-P3d) and P(OEGMA-co-MPDL) (P7, control) on (a and b) A549 cells and (c and d) MiaPaCa-2 cells. 
(a)

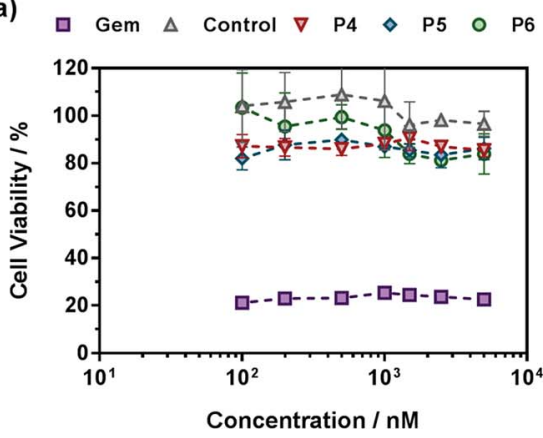

(c)

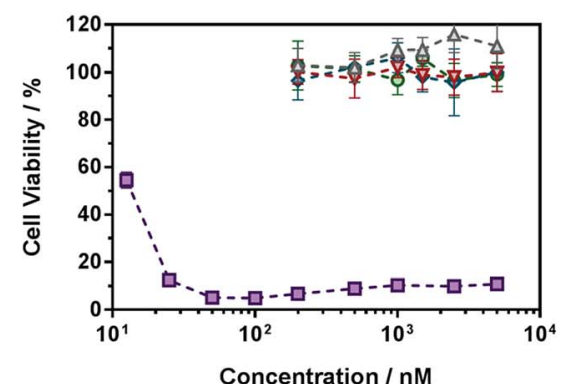

(b)

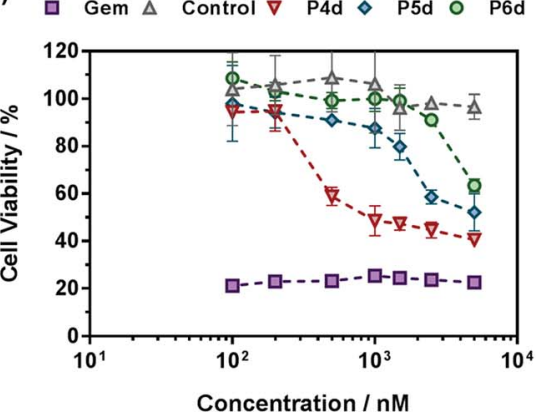

(d)

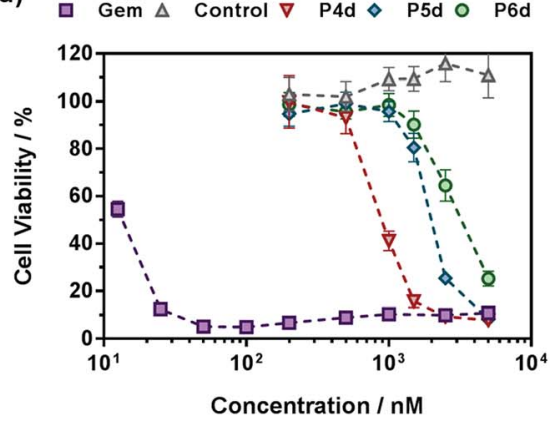

Fig. 9 Cell viability (MTT test) with increasing concentrations of (a and c) Gem, Gem-P(MMA-CO-MPDL) (P4-P6) and P(MMA-CO-MPDL) (P8, control) or (b and d) Gem, Gem-digly-P(MMA-co-MPDL) (P4d-P6d) and P(MMA-co-MPDL) (P8, Control) on (a and b) A549 cells and (c and d) MiaPaCa-2 cells.

resistance against Gem, as evidenced by a plateau at $20 \%$ of cell viability. ${ }^{67}$ Even though results with Gem-P(MMA-co-MPDL) and Gem-digly-P(MMA-co-MPDL) nanoparticles may appear somewhat disappointing, they are crucial to identify key structural parameters to improve the cytotoxicity of the materials.

In a nutshell, the results for both cell lines were in excellent agreement with those obtained from drug release experiments: (i) polymer prodrugs based on $\mathrm{P}(\mathrm{OEGMA}-\mathrm{co}$-MPDL) were more cytotoxic than those based on P(MMA-co-MPDL); (ii) increasing the MPDL fraction in the copolymers led to a decrease in cytotoxicity and (iii) polymer prodrugs based on the diglycolate linker were significantly more cytotoxic than those based on a single amide linkage (see Table $\mathrm{S} 4 \uparrow$ for all $\mathrm{IC}_{50}$ values). Remarkably, the best candidate, Gem-digly-P(OEGMA-coMPDL) P1d enabled reaching the cytotoxic activity of free Gem.

\section{Conclusion}

Degradable vinyl polymer prodrugs were designed by "druginitiated" NMrROP of a methacrylic ester monomer with MPDL from an alkoxyamine derivatized with Gem as an anticancer drug. Two libraries of polymer prodrugs differing by the nature of the methacrylic ester monomer (OEGMA or MMA), the nature of the drug-polymer linker and the MPDL content were prepared. Whereas MMA-based prodrugs formed highly stable nanoparticles upon nanoprecipitation, OEGMA-based prodrugs were water-soluble. The degradation of the copolymer prodrugs was proved under accelerated conditions (i.e., basic hydrolysis) and the degradation level was finely tuned by adjusting the MPDL content. Drug-release profiles in human serum and in vitro anticancer activity against two different cancer cell lines helped to establish structure/activity relationships and select the most favorable structural parameters for having the best activity. We demonstrated that three structural parameters independently governed the anticancer activity: (i) soluble OEGMA-based prodrugs were more cytotoxic than MMA-based counterparts; (ii) the lower the MPDL content, the greater the anticancer activity and (iii) a diglycolate linker afforded greater activity compared to a simple amide bond.

Overall, this unique approach enabled us to combine the best of different worlds: (i) degradability from ring-opening polymerization; (ii) ease of synthesis by a radical polymerization method and (iii) sustained drug release and high anticancer activity by a prodrug approach. Additionally, this approach is versatile and general as it could easily be extended to other polymers, to other pathologies by using different drugs, and to other biologically relevant molecules (e.g., fluorescent dyes, imaging agents) for theranostic applications.

\section{Conflicts of interest}

There are no conflicts to declare.

\section{Acknowledgements}

We thank the French Ministry of Research for the financial support of the PhD thesis of EG and the French National Research Agency (ANR-11-JS08-0005 and ANR-15-CE08-0019) for the financial support of the Master internship and PhD of JT, respectively. The authors thank Julie Mougin and Stéphanie 
Denis (Institut Galien Paris-Sud) for technical assistance in HPLC and cell culture, respectively. Arkema is warmly acknowledged for kindly providing the BlocBuilder $\mathrm{MA}^{\mathrm{TM}}$ alkoxyamine and the SG1 nitroxide. The CNRS is also acknowledged for financial support.

\section{References}

1 J. Nicolas, S. Mura, D. Brambilla, N. Mackiewicz and P. Couvreur, Chem. Soc. Rev., 2013, 42, 1147-1235.

2 O. C. Farokhzad and R. Langer, ACS Nano, 2009, 3, 16-20.

3 V. Delplace, P. Couvreur and J. Nicolas, Polym. Chem., 2014, 5, 1529-1544.

4 J. Nicolas, Chem. Mater., 2016, 28, 1591-1606.

5 R. Tong and J. Cheng, Angew. Chem., Int. Ed., 2008, 47, 48304834.

6 R. Tong and J. Cheng, J. Am. Chem. Soc., 2009, 131, 47444754.

7 R. Tong and J. Cheng, Bioconjugate Chem., 2009, 21, 111-121. 8 R. Tong and J. Cheng, Macromolecules, 2012, 45, 2225-2232.

9 Q. Yin, R. Tong, Y. Xu, K. Baek, L. W. Dobrucki, T. M. Fan and J. Cheng, Biomacromolecules, 2013, 14, 920-929.

10 S. Harrisson, J. Nicolas, A. Maksimenko, D. T. Bui, J. Mougin and P. Couvreur, Angew. Chem., Int. Ed., 2013, 52, 1678-1682.

11 Y. Bao, T. Boissenot, E. Guégain, D. Desmaële, S. Mura, P. Couvreur and J. Nicolas, Chem. Mater., 2016, 28, 62666275.

12 Y. Bao, E. Guegain, J. Mougin and J. Nicolas, Polym. Chem., 2018, 9, 687-698.

13 Y. Bao and J. Nicolas, Polym. Chem., 2017, 8, 5174-5184.

14 Y. Bao, V. Nicolas and J. Nicolas, Chem. Commun., 2017, 53, 4489-4492.

15 D. T. Bui, A. Maksimenko, D. Desmaele, S. Harrisson, C. Vauthier, P. Couvreur and J. Nicolas, Biomacromolecules, 2013, 14, 2837-2847.

16 A. Maksimenko, D. T. Bui, D. Desmaële, P. Couvreur and J. Nicolas, Chem. Mater., 2014, 26, 3606-3609.

17 C. C. Williams, S. H. Thang, T. Hantke, U. Vogel, P. H. Seeberger, J. Tsanaktsidis and B. Lepenies, ChemMedChem, 2012, 7, 281-291.

18 B. Louage, L. Nuhn, M. D. P. Risseeuw, N. Vanparijs, R. DeCoen, I. Karalic, S. VanCalenbergh and B. G. DeGeest, Angew. Chem., Int. Ed., 2016, 55, 11791-11796.

19 J. Nicolas, Y. Guillaneuf, C. Lefay, D. Bertin, D. Gigmes and B. Charleux, Prog. Polym. Sci., 2013, 38, 63-235.

20 G. Moad, E. Rizzardo and S. H. Thang, Aust. J. Chem., 2009, 62, 1402-1472.

21 V. Delplace and J. Nicolas, Nat. Chem., 2015, 7, 771-784.

22 A. Tardy, J. Nicolas, D. Gigmes, C. Lefay and Y. Guillaneuf, Chem. Rev., 2017, 117, 1319-1406.

23 S. Agarwal, Polym. Chem., 2010, 1, 953-964.

24 W. J. Bailey, S. R. Wu and Z. Ni, Makromol. Chem., 1982, 183, 1913-1920.

25 W. J. Bailey, Z. Ni and S. R. Wu, J. Polym. Sci., Polym. Chem. Ed., 1982, 20, 3021-3030.

26 W. J. Bailey, Z. Ni and S. R. Wu, Macromolecules, 1982, 15, 711-714.
27 W. J. Bailey and L.-L. Zhou, Tetrahedron Lett., 1991, 32, 15391540.

28 S. Agarwal and L. Ren, Macromolecules, 2009, 42, 1574-1579.

29 L. Ren, C. Speyerer and S. Agarwal, Macromolecules, 2007, 40, 7834-7841.

$30 \mathrm{~J}$. Undin, A. Finne-Wistrand and A.-C. Albertsson, Biomacromolecules, 2013, 14, 2095-2102.

31 J. Undin, T. Illanes, A. Finne-Wistrand and A.-C. Albertsson, Polym. Chem., 2012, 3, 1260-1266.

$32 \mathrm{H}$. Wickel and S. Agarwal, Macromolecules, 2003, 36, 6152-6159.

33 H. Wickel, S. Agarwal and A. Greiner, Macromolecules, 2003, 36, 2397-2403.

34 H. Shi, L. Liu, X. Wang and J. Li, Polym. Chem., 2012, 3, 11821188.

35 J. Huang, R. Gil and K. Matyjaszewski, Polymer, 2005, 46, 11698-11706.

36 J.-F. Lutz, J. Andrieu, S. Üzgün, C. Rudolph and S. Agarwal, Macromolecules, 2007, 40, 8540-8543.

37 C. Riachi, N. Schüwer and H.-A. Klok, Macromolecules, 2009, 42, 8076-8081.

38 D. J. Siegwart, S. A. Bencherif, A. Srinivasan, J. O. Hollinger and K. Matyjaszewski, J. Biomed. Mater. Res., Part A, 2008, 87A, 345-358.

39 J.-Y. Yuan and C.-Y. Pan, Eur. Polym. J., 2002, 38, 1565-1571. 40 G. G. Hedir, C. A. Bell, N. S. Ieong, E. Chapman, I. R. Collins, R. K. O'Reilly and A. P. Dove, Macromolecules, 2014, 47, 28472852.

41 J. M. J. Paulusse, R. J. Amir, R. A. Evans and C. J. Hawker, J. Am. Chem. Soc., 2009, 131, 9805-9812.

42 Q. Smith, J. Huang, K. Matyjaszewski and Y.-L. Loo, Macromolecules, 2005, 38, 5581-5586.

43 S. Ganda, Y. Jiang, D. S. Thomas, J. Eliezar and M. H. Stenzel, Macromolecules, 2016, 49, 4136-4146.

44 S. Kobben, A. Ethirajan and T. Junkers, J. Polym. Sci., Part A: Polym. Chem., 2014, 52, 1633-1641.

45 G. G. Hedir, C. A. Bell, R. K. O'Reilly and A. P. Dove, Biomacromolecules, 2015, 16, 2049-2058.

46 S. Harrisson, T. P. Davis, R. A. Evans and E. Rizzardo, Macromolecules, 2001, 34, 3869-3876.

47 S. Harrisson, T. P. Davis, R. A. Evans and E. Rizzardo, Macromolecules, 2001, 34, 3869-3876.

48 R. A. Evans and E. Rizzardo, Macromolecules, 1996, 29, 69836989.

49 A.-C. Albertsson and I. K. Varma, Biomacromolecules, 2003, 4, 1466-1486.

50 N. Grabe, Y. Zhang and S. Agarwal, Macromol. Chem. Phys, 2011, 212, 1327-1334.

51 Q. Jin, F. Mitschang and S. Agarwal, Biomacromolecules, 2011, 12, 3684-3691.

52 T. Cai, Y. Chen, Y. Wang, H. Wang, X. Liu, Q. Jin, S. Agarwal and J. Ji, Polym. Chem., 2014, 5, 4061-4068.

53 T. Cai, Y. Chen, Y. Wang, H. Wang, X. Liu, Q. Jin, S. Agarwal and J. Ji, Macromol. Chem. Phys., 2014, 215, 1848-1854.

54 J. Tran, E. Guegain, N. Ibrahim, S. Harrisson and J. Nicolas, Polym. Chem., 2016, 7, 4427-4435.

55 H. Fessi, F. Puisieux, J. P. Devissaguet, N. Ammoury and S. Benita, Int. J. Pharm., 1989, 55, R1-R4. 
56 S. Mura, E. Buchy, G. Askin, F. Cayre, J. Mougin, S. Gouazou, D. Sobot, S. Valetti, B. Stella and D. Desmaele, Biochimie, 2016, 130, 4-13.

57 A. Maksimenko, J. Mougin, S. Mura, E. Sliwinski, E. Lepeltier, C. Bourgaux, S. Lepêtre, F. Zouhiri, D. Desmaële and P. Couvreur, Cancer Lett., 2013, 334, 346-353.

58 L. W. Hertel, G. B. Boder, J. S. Kroin, S. M. Rinzel, G. A. Poore, G. C. Todd and G. B. Grindey, Cancer Res., 1990, 50, 44174422.

59 V. Delplace, E. Guegain, S. Harrisson, D. Gigmes, Y. Guillaneuf and J. Nicolas, Chem. Commun., 2015, 51, 12847-12850.

60 V. Delplace, A. Tardy, S. Harrisson, S. Mura, D. Gigmes, Y. Guillaneuf and J. Nicolas, Biomacromolecules, 2013, 14, 2837-2847.

61 V. Delplace, S. Harrisson, A. Tardy, D. Gigmes, Y. Guillaneuf and J. Nicolas, Macromol. Rapid Commun., 2014, 35, 484-491.
62 V. Heinemann, Y.-Z. Xu, S. Chubb, A. Sen, L. W. Hertel, G. B. Grindey and W. Plunkett, Cancer Res., 1992, 52, 533539.

63 E. Guegain, V. Delplace, T. Trimaille, D. Gigmes, D. Siri, S. R. A. Marque, Y. Guillaneuf and J. Nicolas, Polym. Chem., 2015, 6, 5693-5704.

64 D. Gigmes, P. H. M. Van Steenberge, D. Siri, D. R. D'hooge, Y. Guillaneuf and C. Lefay, Macromol. Rapid Commun., 2018, 1800193.

65 M. Gooyit, M. Lee, V. A. Schroeder, M. Ikejiri, M. A. Suckow, S. Mobashery and M. Chang, J. Med. Chem., 2011, 54, 66766690.

66 E. Guégain, J.-P. Michel, T. Boissenot and J. Nicolas, Macromolecules, 2018, 51, 724-736.

67 R. Ikeda, L. C. Vermeulen, E. Lau, Z. Jiang, K. Sachidanandam, K. Yamada and J. M. Kolesar, Int. J. Oncol., 2011, 38, 513-519. 